\title{
Patentes de Programas de Computador e de Sistemas Informáticos de Jogos Eletrônicos / Patentes de Métodos de Exercício de Actividades Econômicas?
}

\section{SOFTWARE PATENTS AND ELECTRONIC GAMING SYSTEMS / PATENTS OF RULES AND METHODS FOR DOING BUSINESS?}

\author{
João Paulo F. Remédio Marques * \\ Professor Da Faculdade De Direito Da Universidade De Coimbra (Portugal)
}

RESUMO:

O presente trabalho analisa a patenteabilidade das invenções que implicam programas de computador no setor dos jogos electrónicos e dos métodos de fazer negócios e, sendo admitida tal patenteabilidade em determinados casos concretos, procura esclarecer o âmbito de proteção destas patentes. De igual modo, este estudo analisa, subsidiariamente, a proteção dos programas de computador e sistemas de jogos pelo direito de autor.

Palavras-chave: Patentes. Programas De Computador. Jogos. Métodos De Exercício De Actividades Económicas. Âmbito De Proteção.

AbSTRACT: This paper discusses de patentability of software patents in the field of gaming and methods for doing business and, if admissible, analyses the scope of these patents. Additionally, this work also discusses the protection of computer programs and gaming systems by copyright law.

Keywords: Software Patents. Scope Of Protection. Gaming. Methods For Doing Business. Copyright.

\section{SUMÁRIO:}

1. Introdução. Razão de ordem. - 2. Noção de programa de computador. Os algoritmos. As invenções alicerçadas em métodos de fazer negócios por meio de programas de computador. Os conhecimentos exigíveis ao perito na especialidade (na engenharia informática e nas ciências da computação). A questão da falta de actividade inventiva destas invenções. - 2.1. O conceito de invenção e as realidades não patenteáveis. - 2.2. A exclusão da patenteabilidade dos métodos de exercício de actividades económicas. - 2.3. A exclusão da patenteabilidade dos sistemas informáticos e programas de computador (cont.). 3. A insusceptibilidade proteção da patenteabilidade das invenções de métodos do exercício de actividades intelectuais em matéria de jogos. - 4. Balanço da patenteabilidade dos programas de computador, dos métodos de exercício de actividades económicas no domínio dos jogos. - 5. Os problemas quanto à presença de actividade inventiva nas invenções que implicam programas de 
computador. - 6. O alcance do ius prohibendi do titular nas patentes de processo (cont.). A infração indirecta do direito de patente e o ordenamento jurídico português. - 7. Concretização. 8. A tendencial insuficiência da tutela por direito de autor dos programas de computador e sistemas informáticos. - 9. Conclusões.

\section{Introdução. Razão de ordem}

O presente estudo visa discutir o objecto de certas realidades para as quais se busca a concessão de direitos de patente enquanto "candidatas positivas"/“candidatas negativas" a essa patenteabilidade, quais sejam: as invenções que implicam programas de computador, em particular no domínio dos jogos (de casino em linha e fora de linha) e dos demais métodos de fazer negócios.

Desde logo, cumpre analisar de cujos requisitos é que a patenteabilidade destas realidades depende para ser qualificada como constituindo uma solução técnica provida de efeito técnico. Isto porque é este o conceito de invenção que adoto. É então crucial saber quando é que os programas de computador (software) são parte integrante do progresso e das inovações tecnológicas - merecedoras da atribuição deste exclusivo industrial temporário, qual estímulo à manutenção ou incremento das prestações empresariais e esforço intelectivo dos inventores - ou se, pelo contrário, devem estas realidades ser somente relegadas para o universo do subsistema do direito de autor.

A necessidade de segurança jurídica e a previsibilidade das condutas é importante para todos os agentes económicos em concorrência, bem como para o público em geral, atenta a sempre aberta possibilidade de livre utilização destas realidades, quanto limitações interna ou intrínseca ao exclusivo industrial (ou autoral). Daí que tentarei, igualmente, analisar o âmbito de proteção (mais ou menos frustre) destas patentes, confrontando esta tutela com a que decorre da proteção por direito de autor (ou proteção sui generis resultante da matriz autoral).

Estas invenções — assim previamente qualificáveis enquanto alegadas soluções técnicas para problemas técnicos logradas por meio de meios técnicos - e os pedidos de proteção que lhes dizem respeito aumentaram exponencialmente nos últimos anos. Com efeito, em 2013, cerca de $16 \%$ dos pedidos de patente europeia situaram-se no 
domínio das invenções implementadas por programas de computador ${ }^{1}$. Faz-se necessário um esforço harmonizador do regime jurídico - pelo menos entre os tribunais dos Estados contratantes da $\mathrm{CPE}$ e os orgãos jurisdicionais do próprio $\mathrm{CPE}$-, haja em vista, por um lado, o artigo 27. ${ }^{\circ}$, n. $^{\circ} 1$, do Acordo APDIC/TRIPS ${ }^{2}$, por outro, a infrutífera tentativa de retirar a proibição da patenteabilidade dos programas de computador do artigo 52. ${ }^{\circ}$, n..$^{\circ}$, alínea $c$ ), da CPE, por ocasião da Conferência Diplomática de 2000 destinada à Revisão desta Convenção ${ }^{3}$ e, enfim, a rejeição pelo Parlamento Europeu, em Julho de 2005 (com 648 votos e apenas 14 a favor dessa proposta), da proposta de Directiva sobre invenções implementadas em programas de computador (com 648 votos contra e apenas 14 votos a favor dessa proposta).

2. Noção de programa de computador. Os algoritmos. As invenções alicerçadas em métodos de fazer negócios por meio de programas de computador. Os conhecimentos exigíveis ao perito na especialidade (na engenharia informática e nas ciências da computação). A questão da falta de actividade inventiva destas invenções

Os programas de computador constituem um conjunto de instruções para máquinas ${ }^{4}$ susceptíveis de processar informações, as quais são utilizadas directamente

\footnotetext{
* Prof. Dr. Iuris. Professor da Faculdade de Direito da Universidade de Coimbra e da Universidade Lusíada do Porto (Portugal). Professor Titular de Propriedade Industrial e de Direito Processual Civil. Professor Visitante em Universidades do Brasil, Espanha, Macau, Angola, Moçambique. Juiz-Árbitro em litígios de Propriedade Industrial e Direito dos Contratos. Correio electrônico: remedio@fd.uc.pt.

${ }^{1}$ EPO, Annual Report 2013: European Patent Applications (Março 2014). Este nomen (veiculada pelo IEP e pela Comissão Europeia) espelha, desde logo, a interpretação restritiva da proibição prevista no art. 52. ${ }^{\circ}$, n. $^{\circ}$, alínea c), in fine, da CPE, visando legitimar somente exclusão dos processos mentais puros do universo das realidades patenteáveis.

2 O qual proíbe que os Estados contratantes da Organização Mundial do Comércio discriminem o universo das realidades patenteáveis em função do domínio da tecnologia em que estas se possa inserir. Sobre isto, cfr. N. PIRES DE CARVAlHO, The TRIPS Regime of Patent Rights, 3. a ed., Austin, Boston, Chicago, New York, The Netherlands, Wolters Kluwer, 2010, pp. 7-8, pp. 265-266.

${ }^{3}$ Com base na ideia de que esta proibição se revelava obsoleta, tendo em conta a jurisprudência então formada nas Câmaras Técnicas de Recurso do IEP, segundo a qual as invenções que implicam programas de computador são patenteáveis, contanto que produzam um (qualquer) efeito técnico. Cfr., infra, 2.3., para mais desenvolvimentos.
}

${ }^{4}$ J. de OliveIRA AsCensão, Direito Civil-Direito de Autor, Coimbra, Coimbra Editora, 1992, p. 76. 
(em código binário ou código-objecto executável apenas por máquinas) ou indirectamente (em linguagens de alto nível, tais como Cobol, C, C++, Visual Basic etc., ou seja em código-fonte, as quais devem ser compiladas em momento anterior ao da sua inserção) por estas máquinas, tendo em vista a execução de uma determinada função, tarefa ou a obtenção de um certo resultado (p. ex., no domínio dos jogos de casino). Vale isto por dizer que se trata de um acervo de instruções sequenciadas que aplicam (id est, que interpretam e desenvolvem) um algoritmo. É, portanto, errado dizer-se que o programa de computador é uma parte de um CD-ROM de um qualquer outro dispositivo corpóreo susceptível de o prover de aplicações funcionais ${ }^{5}$. Já, por sua vez, o algoritmo é um expediente técnico geral de resolução de um problema, sendo, por isso, orientado para o problema ${ }^{6}$.

O algoritmo traduz assim sequências ou sucessão finita de etapas, com base num número limitado de instruções, claras e objectivamente possíveis, o qual visa produzir um determinado resultado, resolvendo todos os problemas de uma determinada espécie ou classe de problemas. Mas os algoritmos são os elementos essenciais (e a génese da existência) dos programas de computador, visto que aqueles são "traduzidos" numa linguagem "entendida” ou, sobretudo, “executável” pela máquina (o hardware), num programa capaz de ser executado por essa máquina ou por uma rede de máquinas que processem informações, em linha (na Internet) ou fora de linha.

Num sentido mais amplo, os algoritmos (não circunscrito apenas às operações matemáticas) são conjuntos ordenados e sequenciais de todas as instruções precisas, finitas, inequívoca, analíticas, gerais e abstractas, formuladas ex ante, cuja escrupulosa e literal aplicação permite a obtenção do resultado pretendido ou a execução da função desejada ${ }^{7}$. Assim se compreende que os algoritmos não são apenas os algoritmos

\footnotetext{
${ }^{5}$ Tb., neste sentido Graig A. NARD, The Law of Patents, 3. ${ }^{\mathrm{a}}$ ed., New York, Wolters Kluwer, 2014, p. 236; N. PIRES De CARVALHO, The TRIPS Regime of Patent Rights, 3. a ed., 2010, cit., p. 265.

${ }^{6}$ D. JUNGNICKEL, Graphs, Networks and Algorithms, 2. ${ }^{a}$ reimpressão, trad. em língua inglesa, Heidelberg, New York, Springer, 2002, p. 36; J. de OliveIRA AsCEnsão, “A proteção jurídica dos programas de computador", in: Revista da Ordem dos Advogados, ano 50, I, Abril 1990, p. 69 ss., p. 73.

7 J. P. REMÉDIO MARQUeS, Biotecnologia(s) e Propriedade Intelectual, vol. II, 2007, cit., pp. 700-701, nota 1674 (e bibliografia aí referida); J. A. Garcia MARQues/A. G. LourenÇO MARTins, Direito da Informática, 2. ${ }^{\mathrm{a}}$ ed., Coimbra, Almedina, 2006, p. 544 (definindo o algoritmo como sendo uma "sequência finita e não ambígua de instruções para solucionar um problema computável").
} 
ISSN ELETRÔNICO 2316-8080

PATENTES DE PROGRAMAS DE COMPUTADOR E DE SISTEMAS INFORMÁTICOS DE JOGOS

ELETRÔNICOS PATENTES DE MÉTODOS DE EXERCÍCIO DE ACTIVIDADES ECONÔMICAS?

matemáticos, já que podem servir os propósitos de qualquer actividade humana (incluindo no domínio do exercício de actividades económicas e do jogo), pois que a lógica boleana (e os seus símbolos binários 0 e 1) - tal como foi percepcionada por Claude SHANNON, um dos corifeus da computação moderna, em 1937 — não assenta apenas em algoritmos matemáticos. Porém, ponto essencial é saber se a utilização dos algoritmos no desempenho destas actividades económicas autoriza a patenteabilidade das soluções resultantes da execução das instruções determinadas por tais algoritmos. Veremos adiante esta questão.

As alegadas invenções de métodos de fazer negócios por meio de programas de computador ${ }^{8}$ têm sido objecto de proteção por direito de patente em vários países, desde os finais dos anos sessenta do século passado.

Um exemplo paradigmático é a patente dos Estados Unidos da América n. ${ }^{\circ} 3,573,747$, intitulada Institutional Networks Corporation (instinet). Reivindicou-se então um sistema de negociação em bolsa de valores. As ofertas de compra e venda podiam ser efectuadas pelos intermediários financeiros através dos respectivos terminais de computador. O sistema permitia encontrar de forma automática a compatível entre ofertas de compra e propostas de venda de acções e obrigações, de jeito a que, uma vez surpreendida tal adequação, o negócio fosse imediatamente efectuado. As propostas de compra e venda realizadas por meio deste sistema vinculam os oferentes ou proponentes tão logo que era efectuadas e armazenadas na unidade central de processamento de informações dos computadores. Uma outra situação muito polemizada consistiu no caso Amazon.com v. BurnesaandNoble.com, 239 F.3d, 1343, decidido no Federal Circuit, em 2001, relativamente à patente dos E.U.A. n. 5,960,411, intitulada "Method and system for placing a purchase order via a Communications network", vale dizer, a famosa "one-click patent" então titulada pela Amazon, tendo esta 2. ${ }^{\mathrm{a}}$ instância entendido que a patente não fora infringida pois era inválida. Uma variante de tais processos de compra e venda de títulos executados por meio de sistemas computacionais foi a patente britânica n. $^{\circ}$ 1,489,571 (Automated Real-Time Investment Exchanges Ltd), de 1971. Nesta alegada invenção, o sistema estava apto a receber propostas não vinculativas ou expressões de interesses de compra ou venda de imóveis e outros bens. O sistema informático, uma vez enviadas e armazenadas as propostas de compra e venda dos bens, tentava encontrar propostas compatíveis. Quanto isso ocorria, os terminais (máquinas) pelos quais davam entrada as propostas eram colocados em linha, a fim de permitir que os dois mediadores (ou os próprios mandantes) continuassem a negociar. O negócio somente se concretizava (em linha e assim ficava "documentado") quando uma parte aceitava a proposta da outra e teclava um específico comando do terminal do computador para que tal proposta fosse aceita.

\footnotetext{
${ }^{8}$ J. P. RemÉdio marques, Biotecnologia(s) e Propriedade Intelectual, vol. II, Obtenções Vegetais. Conhecimentos Tradicionais. Sinais Distintivos. Bioinformática e Bases de Dados. Direito da Concorrência, Coimbra, Almedina, 2007, pp. 699-700.
} 
À luz da matriz legal e jurisprudencial do IEP e dos seus orgãos jurisdicionais (Divisões de Oposição, Câmaras Técnicas de Recurso e Grande-Câmara de Recurso), a qual não pode deixar de influenciar o direito de patente de português, deve, desde já, observar-se que a patenteabilidade dos programas e das redes de computação respeitantes à execução de métodos de fazer negócios ou de exercer actividades económicas está condicionada à presença, nas reivindicações, de precípuos efeitos técnicos, elementos técnicos, considerações ou contribuições técnicas. O próprio regime jurídico da Propriedade Industrial português, constante do CPI, determina a exclusão da patenteabilidade dos "métodos do exercício de actividades intelectuais em matéria de jogo ou no domínio das actividades económicas, assim como os programas de computadores, como tais, sem qualquer contributo (artigo 52..$^{\circ}$ n. ${ }^{\circ} 1$, alínea $d$ )), do CPI).

\subsection{O conceito de invenção e as realidades não patenteáveis}

Atenta a abertura dinâmica ${ }^{9}$ do conceito de invenção e à luz do seu conceito funcional ${ }^{10}$, cremos que para o direito de patente apenas podem ser protegidas as soluções técnicas de problemas — também eles - técnicos. E uma invenção traduz uma solução técnica (dirigida assim a um problema também ele técnico).

Se é verdade que o ser uma invenção técnica ou esta exibir tecnicidade ou efeitos técnicos significa que para a sua execução e reproductibilidade com resultados constantes (maxime, pelos peritos na especialidade) se faz mister a manipulação

\footnotetext{
${ }^{9}$ F.-K. BEIER, "Zukunftsprobleme des Patentrechts", in: GRUR, 1972, p. 214 ss., p. 216; Alfred KeukenschHriJver, in: R. Busse, Patentgesetz, Kommentar, 7. ${ }^{\mathrm{a}}$ ed., Berlin, De Gruyter, 2013, § 1, anotação à margem n. ${ }^{\circ} 20$, p. 51, segundo o qual: “... der Begriff der Technik muss im Patentrecht dymanisch ("nicht-statisch") verstanden werden"; A. VANZETTI/V. DI CATALDO, Manuale di Diritto Industriale, 7. ${ }^{\mathrm{a}}$ ed., Milano, Giuffrè, 2012, pp. 388-389; R. MoufANG, in: R. SChUlTE, Patentgesetz mit Europäischem Patentübereinkommen, 9. ${ }^{\mathrm{a}}$ ed., Köln, Berlin, Bonn, München, Carl Heymanns Verlag, 2014, § 1, anotação à margem n. ${ }^{0} 19$, pp. 133-134.

${ }^{10}$ Seria inadmissível definir um conceito por meio da utilização de referentes exógenos ao subsistema do Direito aí onde as suas características práticas deve ser utilizadas para permitir a satisfação de pretensões jurídicas e/ou resolver conflitos de interesses. Cfr. R. WANK, Die juristische Begriffsbildung, München, C. H. Beck, 1985, p. 77 ss.
} 
ISSN ELETRÔNICO 2316-8080

PATENTES DE PROGRAMAS DE COMPUTADOR E DE SISTEMAS INFORMÁTICOS DE JOGOS

ELETRÔNICOS PATENTES DE MÉTODOS DE EXERCÍCIO DE ACTIVIDADES ECONÔMICAS?

humanamente controlada das forças da Natureza exteriores à mente humana ${ }^{11}$, de tal maneira que a solução técnica seja materializada numa coisa corpórea (incluindo energia, gás, etc.) - mesmo que a invenção resida no processo de obtenção de um produto - , não é menos verdade que a tecnologia enquanto sector do empreendimento humano deve achar-se aberta a novos objectos ou realidades patenteáveis. Porém, dado que é, não raro, difícil delimitar as realidades que podem ser patenteáveis das restantes — desde logo, pela circunstância de ser duvidoso que apenas o possam ser as realidades cujas considerações de patenteabilidade se baseiam em elementos ou características externas ou fenotípicas —, afigura-se mais razoável permitir a constituição de monopólios temporários de utilização económica da materialização (produtos, processos ou usos) de novas e inventivas contribuições do empreendimento humano em sectores da actividade humana reconhecidos como técnicos por parte do subsistema do direito de patente.

Temos, portanto, uma função limitadora do conceito de tecnologia, exactamente a que possa ser referível a um acervo de realidades e criações técnicas aceitas tradicionalmente pelo direito de patente. $\mathrm{O}$ que significa que uma nova e inventiva área do empreendimento humano desfruta de tecnicidade (e de efeitos técnicos), no sentido do subsistema do direito de patente, se e quando constitui o aperfeiçoamento (ou, pelo menos, a alteração) dos conhecimentos, competências ou aptidões de um sector já havido (e reconhecido) como técnico pelo direito de patente ${ }^{12}$.

Veja-se o caso das invenções biotecnológicas. No dealbar do moderno direito de patente, nos finais do século XIX, a química era, seguramente, um domínio da técnica, cujas soluções eram "candidatas positivas" à patenteabilidade. A indústria química estava, ao tempo, envolvida no desenvolvimento de pigmentos, tendo em vista a sua

\footnotetext{
${ }^{11}$ Isto para evitar que as actividades mentais, as ideias, os processos neurológicos possam ser patenteáveis e objecto de fruição económica exclusiva.

${ }^{12}$ Ralph NACK, Die patentierbare Erfindung unter den sich wandelnden Bedingungen von Wissenschaft und Technologie, Köln, Carl Heymanns Verlag, 2002 , p. 147 ss., p. 306 ss.; Ralph NACK, "Der Erfindungsbegriff - eine gesetzberische Fehlkonstruktion", in: GRUR, 2014, p. 148 ss., p. 149; Jürgen ENSTHALLER, "Muss der Erfindungsbegriff in $\S 1$ PatG und Art. 52 EPÜ reformiert werden?, in: GRUR, 2015, p. 150 ss., 152. Também, R. Nack, in: Haedicke, M./Timmann, H. (ed.), A Handbook on European and German Patent Law, München, Oxford, Baden-Baden, C. H. Beck, Hart, Nomos, 2014, § 2, anotação à margem n. ${ }^{\circ} 65$ ss., pp. 80-82.
} 
utilização na indústria têxtil. Porém, nas primícias do século $\mathrm{XX}$, alguns desses pigmentos evidenciaram promissoras propriedades terapêuticas. Estas descobertas levaram algumas empresas químicas a divergir do "núcleo duro" da sua actividade económica, investindo recursos humanos e financeiros neste novo tipo de empreendimento. Assim, foi logo possível, desenvolver os primeiros antibióticos, tais como a penicilina, a partir desta investigação farmacêutica. Por sua vez, as soluções logradas pela moderna genética molecular alicerçam-se nos resultados obtidos por aquela primeva bioengenharia de matérias biológicas (in casu, ADN, fungos, bactérias e vírus).

O círculo do patenteável constitui assim um continum expansível ${ }^{13}$ resultante de anteriores contribuições do intelecto humano em sectores já abrangidos pelo subsistema do direito de patente: ab initio, as invenções mecânicas; depois, as invenções químicas e, desde a década de setenta do século XX, as invenções biotecnológicas e nanotecnológicas.

De todo o modo, a abertura da patenteabilidade a novas realidades repousou sempre em novas e inventivas (hoc sensu, não óbvias) soluções técnicas resultantes de sectores de actividade económica em cujo seio anteriores empreendimentos humanos criativos já haviam logrado invenções patenteáveis. Das soluções técnicas logradas no domínio da física e da química passou-se para as soluções obtidas no domínio das actividades agrícolas, silvícolas (sem que, quanto as estas fosse, não raras vezes, esgrimido o obstáculo à patenteabilidade, segundo o qual se trataria de realidades equiparáveis aos fenómenos da Natureza) e mineiras e, por último, das diversas biotecnologias, aqui onde o corpus mechanicum da ideia inventiva consiste em matérias biológicas (afinal, spes vitae) manipuláveis pelos peritos na especialidade, a fim de lograr resultados constantes.

\footnotetext{
${ }^{13}$ Salientando, também, esta dimensão, William R. CORNISH, "The International Relations of Intellectual Property", in: Cambridge Lam Journal, vol. 52 n. ${ }^{\circ}$ 1, 1993, p. 46 ss., pp.54-5; Nari LeE, "Patent Eligible Subject Matter Reconfiguration and the Emergence of Proprietarian Norms - The Patent Eligibility of Business Methods", in: IDEA - The Journal of Law and Technology, vol. 45, n. ${ }^{\circ}$ 3, 2005, p. 321 ss., p. 328 ss.
} 
ISSN ELETRÔNICO 2316-8080

PATENTES DE PROGRAMAS DE COMPUTADOR E DE SISTEMAS INFORMÁTICOS DE JOGOS

ELETRÔNICOS PATENTES DE MÉTODOS DE EXERCÍCIO DE ACTIVIDADES ECONÔMICAS?

Eis, pois, uma a um tempo dimensão utilitarista — aí onde se possa reconhecer como benéfico o estímulo do alargamento das realidades patenteáveis - funcional ${ }^{14} \mathrm{e}$ «proprietarista» ${ }^{15}$.

\subsection{A exclusão da patenteabilidade dos métodos de exercício de actividades económicas}

Sempre houve, porém, uma total resistência à patenteabilidade dos métodos de exercício de actividades económicas, especialmente no domínio dos serviços financeiros ${ }^{16}$, visto que os novos empreendimentos "inventivos" no setor das actividades mercantis (v.g., técnicas de organização e de gestão de empresas e de recursos humanos, de estenografia, de armazenamento de escrituração mercantil, livros

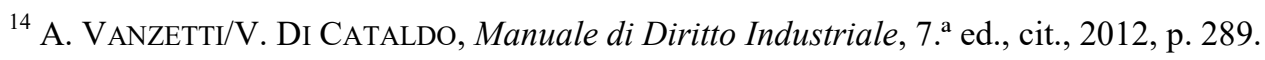

${ }^{15}$ Peter Drahos, A Philosophy of Intellectual Property, 1996, Singapore, Sydney, Dartmouth Publishing Group, Aldershot, 1996, pp. 201-202 (dimensão «proprietarista», esta, alicerçada na primazia éticojurídica da apropriação privada relativamente à utilização livre das soluções técnicas).

${ }^{16}$ R. NACK, Die patentierbare Erfindung unter den sich wandelnden Bedingungen von Wissenschaft und Technologie, cit., p. 180 ss, pese embora a exclusão da patenteabilidade abranja as invenção no domínio da gestão empresarial, em particular os novos e inventivos modelos de negócios e demais empreendimentos neste domínio: cartões de crédito codificados para aquisição de produtos ou serviços a partir de máquinas; métodos que se traduzam numa melhor divisão e organização do trabalho; métodos para determinar e ordenar os clientes a serem servidos, quando estes estão situados em diferentes locais; métodos de publicidade ou de promoção, em geral, de produtos ou serviços; métodos para guardar arquivos, etc. - R. NACK, ob. cit., p. 260 ss., para o desenvolvimento de alguns destes exemplos. Outros exemplos: sistema informático destinado à aquisição mais facilitada de produtos oferecidos por agentes económicos situados noutros países, a partir de catálogos e por meio da língua escolhida pelo potencial adquirente (decisão T 959/03, da Câmara Técnica de Recurso do IEP, no caso International Transactions/ED POOL); sistema de aquisição de produtos que permite mostrar produtos mais baratos de outros que exigem a realização de um leilão electrónico mediante o contacto com os fornecedores, a fim de o preço proposto poder ser mais reduzido (decisão T 711/08, idem, de 1/2/2012, no caso Procurement system/TOSHIBA, $\quad$ http://www.epo.org/law-practice/case-law-appeals/recent/t080711 eu1.html\#q=); método de avaliar as vendas de produtos oferecidos em outlet (decisão T 154/04, idem, de 15/11/2006, no caso Estimating sales activity/DUNS LICENSING ASSOCIATES, L.P., http://www.epo.org/lawpractice/case-law-appeals/recent/t040154ex1.html\#q=); método de avaliar o desempenho de prestadores de serviços em linha (decisão T 1930/06, idem, de 12/03/2010, no caso OnlineBestellsystem/TREBESIUS, http://www.epo.org/law-practice/case-law-appeals/recent/t061930du1.html).
} 
de endereços ${ }^{17}$, de gestão de stocks) nunca foram havidos como "técnicos" no quadro do subsistema do direito de patente. Outrossim, no quadro de determinadas técnicas de cálculo (p. ex., utilizando algoritmos). Que o mesmo é dizer que este continum do universo das realidades patenteáveis - o quid relativamente ao qual se pode dizer que constitui uma invenção -, tal como a tecnologia foi percepcionada para o direito de patente, abrangeu (e ainda atinge) as disciplinas tradicionais da engenharia (mecânica, química, electrotécnica) e de algumas ciências naturais (química, biologia, física) ${ }^{18}$.

Munidos destes fios, por vezes quase imperceptíveis, dos teares da história do direito de patente compreendemos que determinadas realidades tenham sido (e ainda sejam) expressamente excluídas do universo dos “objectos” patenteáveis.

O legislador moderno, pelo menos a partir de meados do século XIX, sempre se preocupou na enunciação de um conjunto de realidades não patenteáveis, id est, um conjunto de realidades que, no quadro do direito de patente, não se subsumem ao conceito de invenção, uma espécie de definição negativa de invenção; o que significa que este legislador não teve o propósito de enunciar positivamente as realidades patenteáveis, atento o continuum tecnológico como tal reconhecido do domínio do patenteável pelo direito de patentes.

Esta linha orientadora não é desmentida pelos casos julgados nos tribunais, em particular nos orgãos jurisdicionais do IEP, designadamente, as decisões T 854/90, de 19/03/1992, da Câmara Técnica de Recurso deste Instituto, no caso Card Reder/IBM ${ }^{19}$. $\mathrm{Na}$ decisão T 931/95, de 8/09/2000, no caso Control of Pension System/PBS Partnership - a propósito de um programa de computador que permitia a gestão e administração de um seguro de capitalização —, a Câmara Técnica de Recurso, posto

\footnotetext{
${ }^{17}$ Conquanto fossem utilizadas, na sua obtenção, determinadas técnicas de desenho e pintura - R. NACK, ob. cit., p. 181.

18 Veja-se, tb., neste sentido, o acórdão do BGH, de 17/10/2001, no caso Suche fehlerhafter Zeichenketten, in: GRUR, 2002, p. 143 ss., p. 144.

${ }^{19}$ Foi aí negada a patenteabilidade de um método que permitia que um vulgar cartão de crédito pudesse ser usado e inserido numa máquina pelo cliente interessado na aquisição de produtos e serviços, em vez de o agente económico em causa fornecer aos clientes um cartão específico para a aquisição de tais produtos ou serviços. Este método, nas palavras deste orgão jurisdicional, ainda quando combinado com uma máquina pertencia (belongs) a uma actividade económica. Com o que foi negada a patenteabilidade a este específico método de autenticação.
} 
ISSN ELETRÔNICO 2316-8080

PATENTES DE PROGRAMAS DE COMPUTADOR E DE SISTEMAS INFORMÁTICOS DE JOGOS

ELETRÔNICOS PATENTES DE MÉTODOS DE EXERCÍCIO DE ACTIVIDADES ECONÔMICAS?

que a "invenção" se situasse no domínio das actividades económicas, decidiu que ela não traduzia uma contribuição inventiva, ao invés, curiosamente, do que ocorreu nos E.U.A. ${ }^{20}$. Com o que, também, cabe concluir que a gestão actuarial, através da matemática, não constitui um sector da técnica tal como é entendido no quadro do direito de patente. Donde, um contributo humano neste domínio não pode conferir patenteabilidade.

Algumas decisões das Câmaras Técnicas de Recurso do Instituto Europeu de Patentes são modelares: T 258/03, de 21/04/2004, no caso Automated Auction Method/HITACHI ${ }^{21}$, T 959/03, de 29/09/2006, no caso International Transactions/ED POOL ${ }^{22}$, T 1284/04, no caso Loan System/KING ${ }^{23}$, de 7/03/2007, T 619/05, de

\footnotetext{
${ }^{20}$ Cfr. Michal LIKHOvSKI, "Fighting the Patent Wars", in: EIPR, 2001, p. 267 ss., p. 270.

${ }^{21}$ A respeito de uma plataforma informática na qual um oferente indicava o preço por ele desejado e um preço máximo de aquisição de certos produtos — foi rejeitada a patenteabilidade de um método de optimização do lucro gerável numa actividade económica, apesar de o algoritmo identificava a melhor oferta para o proposto alienante. Novamente, pode entender-se que tais "técnicas" de optimização ou maximização do lucro não constituem um sector da técnica como tal admitido pelo subsistema do direito de patente. A mesma orientação foi seguida na decisão T 688/05, de 21/11/2007, no caso Ticket Auction System/TICKMASTER: o sistema informático (e o algoritmo que lhe era associado) permitia identificar as ofertas mais vantajosas para o alienante, do ponto de vista da maximização do lucro.

${ }^{22}$ Estava em causa a patenteabilidade de um sistema informático de tornar mais fáceis certas transaç̧ões internacionais de bens, por meio do qual o proposto adquirente poderia peticionar um preço numa qualquer moeda legal (que incluía os custos de transporte e os impostos) e, uma vez efectuada a encomenda o sistema criava uma factura - a Câmara Técnica de Recurso entendeu que os elementos novos do referido sistema informático baseavam-se somente em motivos ou critérios comerciais (commercial considerations).

${ }^{23}$ Discutiu-se, neste caso, a patenteabilidade de um sistema informático que fazia actuar um método de gestão de contratos financeiros. Por exemplo, previa-se que a compensação de um contraente fosse automaticamente recalculada em função de factores tais como a solvência. A Câmara Técnica de Recurso voltou a reiterar a orientação segundo a qual a ideia inventiva baseada num determinado sector de actividade económica é insusceptível de proteção por direito de patente.
} 
30/03/2007, no caso Facilitation of Trasactions in Diamonds/DIAMONDS.NET ${ }^{24}$, T $670 / 07$, de 11/7/2013, no caso Shopping with mobile devide/NOKIA ${ }^{25}$.

De igual sorte, na jurisprudência de vários Estados Contratantes da CPE surpreendem-se múltiplas decisões de exclusão da patenteabilidade de invenções no domínio das actividades económicas, bem como actividades intelectuais em matéria de jogos. Veja-se, inter alia, na Alemanha, a decisão do BGH, de 29/04/2004, o caso Elektronischer Zahlungsverkehr ${ }^{26}$; a decisão do BPatG, de 30/4/2009, no caso Reiseautomat/Travel Automat ${ }^{27}$; a decisão do BPatG, de 8/1/2009 ${ }^{28}$. Outrossim, a decisão do BPatG, de 25/10/2007, no caso Verfahren zum Lottospielen ${ }^{29}$, bem como a da Cour d'appel de Paris, de 28/06/2013, no caso Mr L. v. Publicis Groupe \& RATP ${ }^{30}$.

\footnotetext{
${ }^{24}$ A Câmara Técnica de Recurso voltou a afirmar a orientação de harmonia com a qual a ideia inventiva alicerçada num determinado sector de actividade económica é insusceptível de proteção por direito de patente. A "ideia inventiva" residia no facto de as jóias serem oferecidas por meio de um sítio da Internet, o qual efectuava a sua classificação de acordo com uma multiplicidade de factores com interesse para os potenciais adquirentes.
}

${ }^{25}$ A Câmara Técnica considerou que o efeito consistia em revelar a informação processada e não a informação sobre o estado do próprio aparelho, o que traduzia a ausência de actividade inventiva.

${ }^{26}$ GRUR, 2004, p. 667. Curava-se de um método de emissão de facturas de montantes determinados aos compradores, por meio da Internet, aí onde estes últimos transmitiam o número da factura ao benefíciário, que verificava o montante com o vendedor, que confirmava o pagamento. Neste caso, o BGH entendeu que as "técnicas" de organização de sistemas de compensação de pagamentos não traduzem um qualquer sector da técnica para o direito de patente.

${ }^{27}$ BPatG, $17 \mathrm{~W}$ (pat) 38/08, http://openjur.de/u/240550.html. Curava-se de um catálogo de viagem automatizado: um vídeo sobre alojamentos, excursões, férias e destinos era instalado num servidor da internet, sendo que o cliente usava um léxico disponibilizado pelo sistema para seleccionar e aceder às informações pretendidas.

28 BPatG, 17 W(pat) 61/07, in https://openjur.de/u/237658.html = http://www.jusmeum.de/urteil/bpatg/6c267b3174f63a0f27f8d5fe87f824ec5392fd51fea0f26688d20e9f269 c10bd?page=1. Tratava-se de um método computorizado de aquisição à distância de bens por meio de mensagem de texto e som audível em telemóveis, cujo pagamento era feito através da emissão de uma nota electrónica.

${ }^{29} \mathrm{http} / /$ www.jusmeum.de/urteil/bpatg/aada88f07775c121c97ac34f7538eb98eac57f7aee0df8387fbea7f7d eed394c?page $=1$. Neste caso esgrimiu-se a patenteabilidade de um método de jogar na lotaria: o método habilitava que um jogador situado num local diferente daquele onde o jogo decorria pudesse marcar os seus números por meio da Internet. O Tribunal Federal de Patentes viu no referido processo uma mera forma de facilitação de transacções comerciais, cuja patenteabilidade foi negada.

${ }^{30}$ Curava-se de um dispositivo de comunicação para veicular mensagens publicitárias, via internet, em telemóveis e outros dispositivos, tendo a 2. instancia recusado a patenteabilidade, uma vez que entendeu 
ISSN ELETRÔNICO 2316-8080

PATENTES DE PROGRAMAS DE COMPUTADOR E DE SISTEMAS INFORMÁTICOS DE JOGOS

ELETRÔNICOS PATENTES DE MÉTODOS DE EXERCÍCIO DE ACTIVIDADES ECONÔMICAS?

\subsection{A exclusão da patenteabilidade dos sistemas informáticos e programas de computador (cont.)}

A resposta afirmativa à questão da outorga de direitos de patente a tais supostos inventos no domínio do jogo e dos métodos de exercício de actividades económicas que implicam programas de computador reside assim na sempre difícil distinção entre, por um lado:

(1) Os sistemas ou redes computacionais destinadas a pôr em prática jogos ou sistemas de jogos ou métodos de fazer negócios ou exercer actividades económicas e intelectuais (como na indústria dos jogos de casino), nos quais o contributo técnico elou a actividade inventiva residem no jogo, no método de fazer negócio ou no exercer a actividade económica ou a actividade intelectual (que não na implementação e execução das próprias instruções dadas às máquinas) e, por outro,

(2) Os sistemas ou redes computacionais nos quais o contributo técnico elou os efeitos técnicos estão presentes na própria execução do programa ou das instruções fornecidas às máquinas (v.g., permitindo uma operação mais fácil ou mais rápida do processamento das informações na máquina, com poupança de energia etc.).

Na primeira situação, temos um método de exercer actividade intelectual (no domínio do jogo) ou actividade económica (ou de fazer negócio, in casu, na actividade dos jogos de casino) e um mero suporte corpóreos (programado), através do qual esse método pode ser executado automaticamente, presencialmente ou à distância (p. ex., de uma forma mais rápida, com lucro acrescido etc.).

O problema e a solução técnica acham-se no próprio método de fazer negócio. Dito de outra maneira: no primeiro caso, temos, quanto muito, reivindicações dirigidas directamente ao exercício de actividades intelectuais elou económicas, conquanto com o auxílio de programas de computador e demais dispositivos corpóreos e incorpóreos de rede; no segundo caso, surpreendemos reivindicações dirigidas a realidades (in casu,

tratar-se de um método de comunicação com um puro escopo comercial, cujos meios (embora "técnicos") não resolviam um "problema técnico". Cfr., para a discussão em França, F. POLlAUD-DULIAN, La Propriété Industrielle, Paris, Economica, 2011, pp. 120-121. 
programas de computador) susceptiveis de executar tais actividades por meio de efeitos técnicos e das interaç̧ões funcionais entre os programas de computador e os meios onde eles são executados. No primeiro caso teremos assim programas de computador, métodos de exercer actividades económicas no domínio do jogo "como tais", cuja essência não reside na tecnologia e no contributo tecnológico efectuado nesse continum de empreendimentos humanos de natureza criativa industrial reconhecidos pelo direito de patente como domínios patenteáveis.

Vale isto por dizer: o contributo (do “inventor") surpreende-se apenas num desses domínios de realidades não patenteáveis ${ }^{31}$. Se, porém, houver um contributo adicional num domínio da técnica e da tecnologia, tal como estes conceitos são tradicionalmente aceitos no direito de patente, então pode ser patenteável uma invenção cuja solução (técnica) se situe num domínio não patenteável ${ }^{32}$. Neste último caso poderá haver invenções. Serão estas patenteáveis? Tudo dependerá, no final, da circunstância de tais efeitos técnicos e interacções funcionais entre os programas e as

\footnotetext{
${ }^{31}$ Veja-se, agora neste sentido, a decisão do BGH, de 24/02/2011, no caso Webseitenanzeige, in: GRUR, 2011, p. 610.

${ }^{32}$ Observe-se que por ocasião dos trabalhos preparatórios da Conferência Diplomática de Novembro de 2000, sobre a Revisão da CPE, fora proposta a revogação da proibição da patenteabilidade dos programas de computador "como tais" - alegadamente para harmonizar o normativo com o disposto no artigo 27.", n. ${ }^{\circ}$ 1, do Acordo TRIPS. Porém, pouco antes do início desta Conferência Diplomática, as delegações da França, Dinamarca e Alemanha (tão logo apoiadas por todas as restantes delegações da União Europeia, à excepção da Áustria) propuseram o adiamento da exclusão da menção dos programas de computador "como tais" enquanto realidades não patenteáveis. Assim, no dia 17/11/2000, em Bruxelas (três dias antes do início desta Conferência Diplomática), as delegações de 15 Estados-Membros (mais de dois terços do total dos Estados então Membros) decidiram adiar tal discussão ... até hoje. Cfr. R. NACK/PhÉLIP, "Bericht über de Diplomatische Konferenz zur Revision des Europäischen Patentübereinkommens München 20. - 29 November 2000", in: GRUR Int., 2001, p. 322. Este critério parece achar-se próximo do que tem sido propugnado, recentemente, na doutrina britânica, scilicet, o do "domain approach", sobretudo, a partir do caso Aerotel Ltd v. Telco Holdings Ltd (2006), Symbian Ltd v. Comptroller General of Patents, Designs and Trade Marks (2008) e AT\&T Knowledge Ventures LP v. Comptroller General of Patents, Designs and Trade Marks (2009), Cfr. R. OnSLOw, "Software Patents - A new approach", in: $E I P R, 2012$, p. 710 ss., p. 711, segundo o qual, se é razoável admitir que um programa de computador seja escrito ao derredor de um específico propósito, um programa que seja muito geral ou abstracto ou mostre ser aplicável a múltiplos domínios ou sectores de actividade, então isso significa que se situa num domínio não patenteável, ou seja, o das ciências computacionais. O contributo técnico de uma invenção não deve ser repelido somente pela mera circunstância de este se achar ao serviço de um método negocial ou de uma actividade económica.
} 
ISSN ELETRÔNICO 2316-8080

PATENTES DE PROGRAMAS DE COMPUTADOR E DE SISTEMAS INFORMÁTICOS DE JOGOS

ELETRÔNICOS PATENTES DE MÉTODOS DE EXERCÍCIO DE ACTIVIDADES ECONÔMICAS?

máquinas (e demais interfaces) ou sistemas de rede serem, ou não, evidentes para os peritos na especialidade.

Estas invenções devem assim exibir efeitos técnicos. Esta exigência é, como vimos, natural e por isso mesmo intrínseca ao subsistema do direito de patente, uma vez que as invenções são soluções técnicas para problemas (também eles) técnicos, as quais são logradas por meio da manipulação humana controlada das forças naturais. E o Regulamento de Execução da CPC determina que a descrição da invenção deve "precisar o domínio técnico a que se refere a invenção" (artigo $27 .^{\circ},{ }^{\circ}{ }^{\circ} 1$, alínea a), do referido Regulamento de Execução) ${ }^{33}$. Que tipo de efeitos técnicos? A jurisprudência do IEP - que influencia a jurisprudência portuguesa — faz depender o ser um programa de computador (ou um sistema informático uma invenção (questão ulterior é saber se essa invenção desfruta de novidade e de actividade inventiva) da circunstância de, a mais da presença de tecnicidade (ou de efeitos técnicos na sua execução), essa execução implicar a causação de modificações físicas ou interacções corpóreas entre a máquina (hardware), onde o programa é executado, e o próprio programa ${ }^{34}$.

33 Cfr. a versão em língua portuguesa deste Regulamento em http://www.marcasepatentes.pt/files/collections/pt_PT/1/6/27/Regulamento\%20Execu\%C3\%A7\%C3\%A 3o\%20Conven $\%$ C3\%A7\%C3\%A30\%20Munique $\% 20-\% 20$ Patente $\% 20$ Europeia.pdf.

Ora, o artigo 164. ${ }^{\circ}$, n. $^{\circ}$ 1, da CPE determina, por sua vez, que o Regulamento de Execução da CPE faz parte integrante desta Convenção. Do mesmo jeito, o artigo 62. ${ }^{\circ}$, n. $^{\circ} 3$, do CPI determina que: "As reivindicações definem o objecto da protecção requerida, devendo ser claras, concisas, correctamente redigidas, basear-se na descrição e conter, quando apropriado: Um preâmbulo mencionando o objecto da invenção e as características técnicas necessárias à definição dos elementos reivindicados, mas que, combinados entre si, fazem parte do estado da técnica; b) Uma parte caracterizante, precedida da expressão «caracterizado por» e expondo as características técnicas que, em ligação com as características indicadas na alínea anterior, definem a extensão da protecção solicitada" — os itálicos são meus.

${ }^{34}$ Descrever um algoritmo - ou seja, uma sequência de etapas para resolver um problema - em códigoobjecto (e código-fonte) não traduz um empreendimento técnico no sentido do subsistema jurídico do direito de patente; mas a presença desse algoritmo no quadro de u outro empreendimento técnico não constitui obstáculos à patenteabilidade deste último (produto ou processo); em sentido análogo R. NACK, in: M. Haedicke/H. Timann, Patent Law, A Handbook, 2014, cit., § 2, anotação à margem n. ${ }^{\circ}$ 250, p. 115. Tb. no Brasil a doutrina mais influente entende que os elementos técnicos respeitantes ao programa de computador podem ser considerados para o efeito de apurar se há, ou não, uma contribuição para o estado da técnica e que o critério do objecto técnico se encontra satisfeito e se a contribuição contida no programa reivindicado for usada num sistema específico que compreenda máquinas de tratamento da 
Todavia, ainda quando exibem tais interacções corpóreas (v.g., entre os sinais eléctricos, ópticos etc. e os demais componentes da própria máquina ou da rede de computadores onde são executados), e embora revelem efeitos técnicos, terá de convirse que o carácter técnico passível de conferir o estatuto de invenção a esta realidade deverá ser surpreendido alhures, ou seja, na causação de ulteriores modificações tangíveis situadas para além do quadro das normais interacções físicas entre o programa e a máquina (qual efeito técnico suplementar, para além dos normais efeitos técnicos observados na execução de quaisquer programas de computador em suportes corpóreos ou na execução em linha) ${ }^{35}$. Pois, somente a este outro nível é possível predicar a existência do "further tehnical effect", de que fala o $\S 6.6$ da decisão T 1137/97, no caso Computer program product/IBM, tirada pela Câmara Técnica de Recurso do IEP ${ }^{36}$. Decisão que marca, ainda hoje, o critério de cuja verificação se faz depender a existência de uma invenção ${ }^{37}$.

informação, dispositivos, instrumentos ou equipamentos periféricos baseados em técnica digital ou analógico, além de que se faz necessário que a contribuição exiba efeitos técnicos, ou seja, actuações concretas externas ou internas ao sistema — assim, Denis BorgEs BARBOSA, Tratado da Propriedade Intelectual, Tomo III, A Proteção do Software. Do sigilo dos Testes para Registros de Comercialização. Topografia de Circuitos Integrados, Rio de Janeiro, Lumen Juris, 2010, p. 1998.

${ }^{35}$ O paradoxo é o seguinte: a doutrina e os tribunais, no quadro da CPE (e mesmo no Reino Unido) usam os operadores "efeito técnico" e "contributo técnico" para excluir do universo do patenteável realidades que, tal como os computadores e programas de computador per se, são inerentemente realidades técnicas.

${ }^{36}$ J. P. REMÉDIO MARQUES, Biotecnologia(s) e Propriedade Intelectual, Vol. II, 2007, cit., pp. 752-753. De acordo com esta decisão: "A computer program claimed by itself is not exclude from Patentability if the program, when running on a Computer or loaded into a Computer, brings about, or is capable of bringing about, a technical effects which goes beyond the «normal» physical interactions between the program (software) and the computer (hardware) on which it is run". Cfr., acerca do cumprimento deste requisito, Rui GOMES/RUi BENTO/JOÃO MARCELINO/RICARDO PEREIRA/ANDRÉ ANDRADE, Invenções implementadas por computador - Guia de Legislação e Prática de Exame no INPI para a área das IIC, Instituto Nacional da Propriedade Industrial, Junho de 2014, in: http://www.marcasepatentes.pt/files/collections/pt_PT/1/300/301/Manual\%20das\%20Inven\%C3\%A7\%C 3\%B5es\%20Implementadas\%20por\%20Computador\%20\%28IIC\%29\%202014.pdf.

37 C. DESChAMPS, "Patenting Computer-related Inventions in the US and in Europe: The Need for domestic and International Legal Harmony", in: EIPR, 2011, p. 103 s., pp. 111-112; A. GROSCHE, "Software Patents - Boon or Bane for Europe?", in: International Journal of Law and Information

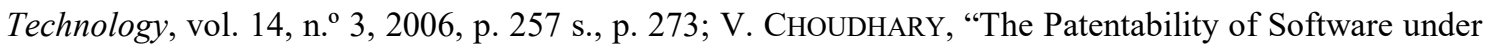
Intellectual Property Rights: an Analyis of US, European and Indian Intellectual Property Rights", in: EIPR, 2011, p. 435 s., pp. 442-443; S. STERCKX/J. COCKBAIN, Exclusions from Patentability -How Far Has the European Patent Office Eroded Boundaries?, Cambridge/New York etc., Cambridge University Press, 2012, pp. 80-83. Observe-se, ademais, que em sede de uniformização de jurisprudência, a Decisão 
ISSN ELETRÔNICO 2316-8080

PATENTES DE PROGRAMAS DE COMPUTADOR E DE SISTEMAS INFORMÁTICOS DE JOGOS

ELETRÔNICOS PATENTES DE MÉTODOS DE EXERCÍCIO DE ACTIVIDADES ECONÔMICAS?

As próprias Directrizes para Exame do IEP reflectem esta jurisprudência, pois nelas preceituam que: "A computer program claimed by itself is not excluded from patentability if it is capable of bringing about, when running on or loaded into a computer, a further technical effect going beyond the "normal" physical interactions between the program (software) and the computer (hardware) on which it is run" ... e que "The normal physical effects of the execution of a program, e.g. electrical currents, are not in themselves sufficient to lend a computer program technical character, and a further technical effect is needed. The further technical effect may be known in the prior art." ${ }^{38}$. Que o mesmo é dizer que sempre uma invenção constitua uma mistura de elementos técnicos $e$ não técnicos (in casu, etapas ou fases de jogar jogos de casino e fazer as concomitantes apostas), essa invenção somente será patenteável se, de acordo com as circunstância do caso, os elementos ou as características técnicas inerentes a esse programa ou sistema informático assumirem um especial significado ou importância para superar a exclusão da patenteabilidade dos programas de computador ainda quando associados a métodos de exercício de actividades económicas ou métodos de jogos ${ }^{39}$.

Ora, tal ocorre sempre que:

(1) o programa de computador afecta a execução de processos que têm lugar fora do computador (ou do sistema informático);

(2) o programa opera ao nível da "arquitectura" do próprio computador ou do sistema informático, independentemente dos dados ou informações a processar ou da execução das aplicações;

(3) o programa conduz o computador (ou o sistema informático) a operar de uma nova maneira;

G 3/08, de 12/05/2010, da Grande-Câmara de Recurso do IEP confirmou, na prática, aquela jurisprudência tirada na Decisão T 1137/97. Isto dito, embora esta Grande-Câmara tenha recusado pronunciar-se sobre o tema, já que se limitou a fundamentar a sua decisão (contida em 55 páginas) na circunstância de não vislumbrar qualquer divergência jurisprudencial que carecesse de uma uniformização judicativa.

${ }^{38}$ Part G, Cap. II, n. ${ }^{0}$ 3.6. (Janeiro de 2016), consultáveis em http://www.epo.org/law-practice/legaltexts/html/guidelines/e/g_ii_3_6.htm.

${ }^{39}$ Neste sentido, veja-se a Decisão T 1543/06, da Câmara Técnica de Recurso do IEP, de 29/06/2007, no caso Game machine/Gameaccount, acessível em https://www.epo.org/law-practice/case-lawappeals/recent/t061543eu1.html. 
(4) o programa aumenta a velocidade ou a confiança no operar desse computador (ou do sistema informático);

(5) o programa de computador permite superar um problema conhecido e identificado em computadores ou em sistemas informáticos, que não apenas "contornar" (circumvent) esse problema ${ }^{40}$.

Por vezes, como acima dissemos, está apenas em causa saber se o efeito técnico reside na "arquitectura" do programa de computador — independentemente da natureza ou aplicação dos dados que são processados (p. ex., dados para fazer apostas) — ou do sistema informático, pois, neste caso, tal realidade já pode constituir uma "candidata" a obter direito de patente.

Pelo contrário, não haverá invenção quando, por meio de uma rede de computadores, se enviam mensagens para outros computadores, pelas quais são transmitidas informações em linha, sem que daí resulte uma maior eficiência no mecanismo computacional de transmissão ou uma nova ou aperfeiçoada maneira de, em termos técnicos (p. ex., de uma forma mais rápida), os computadores ou o sistema

\footnotetext{
${ }^{40}$ Assim, no recente caso, Cranway Ltd v. Playtech Ltd \& Others, decidido pelo High Court (Patents Court) de Inglaterra e País de Gales, de 7/9/2009, in: Fleet Street Reports, 2010, p. 3 s. Neste ilustrativo caso (curava-se de um programa de computador destinado a auditar e a verificar o cumprimento das regras de jogos em linha, prevenindo a batota), o High Court declarou a nulidade de uma patente respeitante a um sistema de verificação de jogos em linha. O juiz LEWINSON entendeu que o único contributo da sociedade Cranway para o estado da técnica fora a ideia de jogar em linha (e à distância) com dinheiro real ("real money") e que o único contributo técnico residia no software (cuja "arquitectura" era, de resto, já conhecida), pelo que decidiu que se tratava de um programa de computador "como tal", e que a única contribuição do titular da patente consistiu em resolver um problema de exercer uma actividade económica, realidade cuja patenteabilidade é excluída no quadro do ordenamento britânico, talqualmente em sede da Convenção Sobre a Patente Europeia (art. 52. ${ }^{\circ}$, n. ${ }^{\circ}$ 2, alínea $c$ )), em Portugal. Tb., neste sentido, nos casos Aerotel v. Telco, tirado no Court of Appeal (in: R.P.C., 2007, p. 7 s.) e Symbian Ltd v. Comptroller General of Patents, Designs and Trademarks, tirado no Court of Appeal (Lord NeUberger), em 8/10/2008 (ivi, 2009, p. 1 s. = http://www.bailii.org/ew/cases/EWCA/Civ/2008/1066.html); idem, o Hight Court (Patents Court), de Inglaterra e País de Gales, de 4/9/2013, no caso Lantana Ltd v. Comptroller General of Patents [2013] EWHC 2673 (Pat), http://www.bailii.org/ew/cases/EWHC/Patents/2013/2673.html. Cfr. L. BENTLEY/B. SHERMAn, Intellectual Property Law, 4. ${ }^{a}$ ed., Oxford, New York, Oxford University Press, 2014, pp. 465471; ibidem, no caso HTC Europe Co. Ltd v. Apple Inc., do Court of Appeal [2013] EWCA Civ $451=$ R.P.C, 2013, p. 30 ss. Cfr. N. FOX/W. CORBETT, "UK and EPO Approaches to Excluded Subject-Matter and Inventive Step: Are Aerotel and Pozzoli Heading for the Rocks?", in: EIPR, 2014, p. 569 ss., p. 570 (o tribunal concluiu que a os visores das máquinas passavam a funcionar de uma forma nova $\mathrm{e}$ aperfeiçoada em virtude da execução do programa de computador).
} 
informático executarem o processamento das informações ${ }^{41}$. Muitas vezes, o "coração" da invenção reivindicada respeita a programas de computador executáveis em computadores ou sistemas informáticos convencionais ligados por redes também elas convencionais.

Nestes casos, a contribuição constante das reivindicações reside tão só em realidades excluídas de patenteabilidade, como é o caso dos métodos de exercício de actividades económicas ou em matéria de jogos ${ }^{42}$.

Assim, poderemos dizer que - ainda que a questão releve sobretudo na análise da novidade e da actividade inventiva ${ }^{43}$ destas alegadas invenções - a recusa da patenteabilidade dos programas de computador "como tais" significa a rejeição da proteção a programas de computador (e sistemas informáticos) cujas características e funções são comuns a todos os programas de computador, sendo automaticamente associadas à utilização de programas de computador (e sistemas informáticos) em dispositivos corpóreos (ou em linha) de processamento de dados ou informações ${ }^{44}$.

\section{A insusceptibilidade proteção da patenteabilidade das invenções de métodos do exercício de actividades intelectuais em matéria de jogos}

\footnotetext{
${ }^{41}$ Veja-se, neste sentido, recentemente, a decisão do High Court de Inglaterra e País de Gales (Patents Court), de 4/9/2013, cujo relator foi o Juiz BIRSS, no caso Lantana Ltd's Application UK Patents Court, [2013] EWHC 2673 (Pat) — § 30 s. da decisão. O texto integral do acórdão pode ser consultado em http://www.bailii.org/ew/cases/EWHC/Patents/2013/2673.html.

${ }^{42}$ Cfr. a citada decisão do High Court no caso Lantana Ltd's Application UK Patents Court, [2013] EWHC 2673 (Pat), na qual se concluiu que, substancialmente, as reivindicações respeitavam a programas de computador executáveis em computadores convencionais ligados por uma rede informática convencional, aí onde o programa em causa apenas permitia deslocar dados ou informações entre os terminais através de técnicas — também elas convencionais — de transmissão de tais dados, maxime, por correio electrónico. $\mathrm{O}$ acesso a informações contidas em computadores por meio de uma conexão contínua ou permanente, não obstante fosse um problema técnico, havia sido "evitado" ou "contornado" pelo requerente por meio da utilização de técnicas convencionais ( $\$ 41$ da decisão), motivo por que foi mantida a decisão de rejeição do pedido de patente anteriormente emitida pelo Comptroller General of Patents, Designs and Trademarks, pois que se tratava de um "Computer program as such" (Secção 1(2)(c) do Patents Act de 1977).

${ }^{43}$ Assim, R. Nack, in M. HaedickE/H. Timmann (eds.), Patent Law - A Handbook, München, BadenBaden, Portland, C. H. Beck, Hart Publishing, Nomos, 2014, p. 117.

${ }^{44}$ F.-W. ENGEL, “Über «Computerprogramme als solche»”, in: GRUR, 1993, p. 194 ss., p. 198.
} 
Vejamos as patentes que reivindicam métodos e sistemas de jogos de casino por meio da execução de programas de computador e sistemas informáticos. Como vimos, o artigo 52. ${ }^{\circ},{ }^{\circ}{ }^{\circ}$, alínea $d$ ), do CPI exclui a patenteabilidade "dos métodos do exercício de actividades intelectuais em matéria de jogos ou no domínio de actividades económicas".

A ratio desta proibição parece alicerçar-se na ideia segundo a qual as invenções logradas no domínio da gestão e organização empresarial, em particular os novos e inventivos modelos de actividades económicas não constituem inovações do domínio da técnica, tal como este é entendido no direito de patente ${ }^{45}$.

Vale dizer: cura-se de inovações em domínios não técnicos da actividade humana, aí onde a liberdade de iniciativa económica aconselha a não conceder direitos de exclusivo ${ }^{46}$. Dito de outra maneira: as criações humanas - scilicet, as criações do intelecto humano - respeitantes às regras de jogar jogos não traduzem qualquer sector técnico ou tecnológico entendido como tal para o direito de patente. É irrelevante, por outro lado, se um certo objecto for criado para o propósito de jogar um jogo; mas já integrará o acervo das realidades patenteáveis, por exemplo, um novo material ou componente electrónico usado para executar o jogo.

Donde, qualquer contributo do intelecto humano neste particular sector constitui um contributo não técnico tal como este é entendido no domínio do direito de patente. Por exemplo, se um novo dispositivo de inserção de moedas numa máquina de jogo oferece uma nova visualização das figuras colocadas em linha, por ocasião da obtenção de um jacpot na posição ganhadora, a patenteabilidade deve ser negada, por virtude de a ideia inventiva residir apenas nessa nova ideia de disposição das figuras enquanto ideia de exercício de uma actividade intelectual em matéria de jogo ${ }^{47}$.

\footnotetext{
${ }^{45}$ R. NACK, Die patentierbare Erfindung unter den sich wandelnden Bedingungen von Wissenschaft und Technologie, cit., p. 306 ss.

${ }^{46}$ F. Pollaud-Dulian, La Propriété Industrielle, cit., 2011, p. 119.

${ }^{47}$ Cfr. a decisão do BPatG, de 22/11/2004, $20 \mathrm{~W}$ (pat) 10/03, no caso Jackpotzuwachs, in: GRUR, 2005, p. $493=$ http://www.softwarepatentnews.de/pdf/2010_03.pdf.
} 
De igual jeito, deve ser negada a patenteabilidade a um programa de computador em matéria de jogos (in casu, o Pokemón), que interage com um relógio, destinado a tornar mais surpreendente e imprevisível a junção ou a combinação de caracteres. Isto porque a implementação de regras de um jogo, conquanto por meio de programas de computador ou sistemas informáticos, não traduz um contributo técnico considerado como tal para o direito de patente ${ }^{48}$.

\section{Balanço da patenteabilidade dos programas de computador, dos métodos de exercício de actividades económicas no domínio dos jogos}

Em suma, à parte algumas excepções, a exclusão dos programas de computador e dos métodos de exercício de actividades intelectuais em matéria de jogos ou no exercício de actividades económicas desvela a ideia de harmonia com a qual não existe, neste tipo de eventualidades, qualquer contributo técnico no sentido do direito de patente, seja na implementação de algoritmos, regras de jogo ou na facilitação de transacções comerciais ou gestão de clientes e/ou de contratos ou a optimização de vendas ou de prestação de serviços.

Com efeito, a patenteabilidade de programas de computador tem sido outorgada nos casos de programas que, designadamente: controlam máquinas, componentes de máquinas ou outros dispositivos; processam ou filtram digitalmente sinais; processam sinais digitais; controlam e simulam operações e geram dados para operar de máquinas; controlam outros programas ou circuitos; recuperam operações e dados após falhas de sistemas; controlam periféricos e outros dispositivos; simulam e criam objectos ou figuras tridimensionais e prevêem as respectivas propriedades.

Ao invés, essa patenteabilidade tem sido negada nas hipóteses, designadamente, de programas que:

a) processam texto e/ou folhas de cálculo;

b) processam programas de tradução de escrita em diferentes línguas;

\footnotetext{
${ }^{48}$ Neste sentido, veja-se a decisão T 0012/08, de 6/02/2009, da Câmara Técnica de Recurso do IEP, no caso Game machine and storage medium therefor/NINTENDO, acessível em https://www.epo.org/lawpractice/case-law-appeals/recent/t080012eu1.html.
} 
c) operam ou permitem sistemas de pagamentos electrónicos;

d) calculam preços, quantias ou outras tarifas ou encargos;

e) permitem a visualização de mapas ou outros dados;

f) operam sistemas de conversão em aquisições em linha de produtos ou serviços;

g) gerem carteiras de investimento;

h) permitem a optimização dos lucros de investimentos;

i) gerem o tempo, pessoas ou stocks de mercadorias.

$\mathrm{Na}$ verdade, nestes últimos casos, como dissemos, o alegado "contributo técnico" e/ou "actividade inventiva" residem no jogo, no método de fazer negócios ou no exercício da concreta actividade económica - lá onde o programa é um mero suporte por meio do qual o método pode ser executado automaticamente - e não nas instruções fornecidas às máquinas ou aos sistemas em linha. Uma invenção não é "candidata positiva" à patenteabilidade apenas porque a execução da regra reivindicada implica a utilização de computadores.

Pois, se as invenções que implicam programas de computador (in casu, no domínio dos jogos e das inerentes actividades económicas) incluem reivindicações destinadas a solucionar problemas surpreendíveis nos sectores da tecnologia ligados às ciências da engenharia, à física, à química ou à biologia ${ }^{49}$, então tais invenções integram o conjunto de "candidatos positivos" à patenteabilidade. Questão diversa que abordaremos seguidamente - é saber se tais invenções desfrutam de novidade e, sobretudo, de actividade inventiva, não se tornando evidentes ou óbvias para qualquer perto na especialidade.

\section{Os problemas quanto à presença de actividade inventiva nas invenções que implicam programas de computador}

\footnotetext{
${ }^{49}$ Neste sentido, decisão do BGH, no caso Suche fehlerhafter Zeichenketten, in: GRUR, 2002, p. 143; idem, no caso Wiedergabe topographischer Informationen, in: GRUR, 2011, p. 125.
} 
Coisa diversa - a mais de se poder concluir que o programa de computador ou o sistema informático providos de suportes corpóreos constitui uma invenção consiste em perscrutar se tais invenções não integram o estado da técnica e, sobretudo, se essas invenções não são evidentes para os peritos na especialidade.

$\mathrm{Na}$ verdade, atenta a enorme difusão da utilização de programas de computador, normalmente como instrumentos de outras invenções (como parece acontecer no caso sub iudice, uma vez que os sistemas de jogos reclamam, para a sua execução, a presença de muitos outros dispositivos periféricos, para além da Unidade Central de Processamento e da Unidade de Controlo), assiste-se, não raro, a uma homogeneização e padronização dos códigos ou das linguagens que definem a forma através da qual as informações (in casu, sobre as apostas, prémios, pagamentos etc.), cujo processamento é almejado, são guardadas e os códigos e as instruções que determinam os processos e as funções que têm como objecto os dados ou informações adrede armazenados ou mobilizados.

Outro tanto, esta homogeneização surpreende-se nos códigos que controlam o acervo de sinais que racionalizam o espaço na memória do computador (ou outro suporte) e nos códigos que controlam o conjunto de sinais que desencadeiam a actuação dos processos ou das funções desejadas a partir dos dados armazenados naquela memória. Isto sem esquecer que a peça gráfica constante do fascículo da patente, denominada descrição é, em regra, insuficiente (como parece ser no caso sub iudice), uma vez que o requerente da proteção omita a divulgação dos código-fonte, bem como alguns outros aspectos do programa, v.g., os processos e as funções executadas sobre os dados (id est, as apostas); os sinais de controlo que permitem atribuir espaço na memória da máquina para que para que os dados sejam processados; os sinais de controlo que provocam a execução dos processos ou das funções desejadas; a identificação da fonte dos dados, os meios pelos quais os dados são introduzidos; a indicação das estruturas dos dados usados pelo computador (ou pelo sistema informático) para representar e armazenar os dados; a indicação da "arquitectura do programam" (p. ex., se há dados previamente introduzidos que serão chamados quando outros dados forem introduzidos; a indicação da natureza dos dados após terem sido 
processados; os modos de organização, disposição e selecção dos dados; os tipos de modificações susceptíveis de atingir os dados após o processamento etc).

Por outro lado, mesmo quando não os omite (p. ex., a forma como os dados são armazenados e processados, a descrição do propósito geral do programa; a identificação dos suportes corpóreos e demais periféricos ou interfaces; as vantagens atingidas por algum ou alguns dos meios descritos e as razões que justificam essas vantagens), o requerente da proteção (e, depois, o titular da patente) corre o sério risco de se formar um desmesurado âmbito (tecnológico) de proteção da patente, o qual não se acha suportado pelas reivindicações. O mesmo acontecendo, não raro, mesmo quando as reivindicações são formuladas em termos abstractizantes ${ }^{50}$.

É sabido que a determinação da ausência ou da presença de actividade inventiva depende de uma particular circunstância: saber se o perito na especialidade, possuidor da perícia e dos conhecimentos técnicos exigíveis no sector a que a invenção diz respeito (in casu, engenheiro informático e perito em jogos de casino), seria, ou não, naturalmente conduzido à solução técnica reivindicada, ou, pelo contrário, encararia essa solução como uma alternativa disponível, se e quando fosse confrontado com o problema técnico que a invenção em causa visou resolver. No domínio da engenharia computacional, o engenheiro informático é o sujeito a quem cabe desenvolver sistemas informáticos dirigidos à resolução de específicos problemas técnicos.

O paradigma técnico actual que domina a concepção de programas de computador é um paradigma (holístico) orientado para o objecto (object-oriented paradigm) ${ }^{51}$. De acordo com este modelo (que também é um instrumento heurístico), ao engenheiro informático é oferecida a possibilidade de criar sistemas relativos a um "objecto-Tipo", que traduz os elementos essenciais do sistema informático, impedido que o perito fique limitado pela observância as específicas linguagens de programação e

\footnotetext{
${ }^{50}$ Cfr. J. P. RemÉDIo Marques, Biotecnologia(s) e Propriedade Intelectual, vol. II, 2007, cit., pp. 818189.

${ }^{51}$ Lance D. ReICH, "One Skill in the Art in Software Engineering: The Rising Tiude", in: Mitt, 2003, p. 49 s., p. 51.
} 
ISSN ELETRÔNICO 2316-8080

PATENTES DE PROGRAMAS DE COMPUTADOR E DE SISTEMAS INFORMÁTICOS DE JOGOS

ELETRÔNICOS PATENTES DE MÉTODOS DE EXERCÍCIO DE ACTIVIDADES ECONÔMICAS?

pela natureza das máquinas (ou dos dispositivos em linha), aí onde o sistema irá ser executado $^{52}$.

Cura-se de um modelo que centra a atenção nos processos abstractizantes do "domínio" ou "sector" do problema a resolver, aí onde a atenção do programado é centrada nas características estruturais e comportamentais de elementos do mundo real (v.g., pessoas, dados, periféricos, redes de computadores), subsumindo essas entidades do mundo real a "classes" e a "objectos", os quais se encontram dispostos no sistema de harmonia com a observância de determinados princípios ${ }^{53}$.

Ora, cada "objecto" possui três componentes: a estrutura dos dados, que define os atributos ou características do "objecto" e a forma como cada característica é armazenada; um conjunto de funções ou operações executáveis por esse "objecto"; e uma interface, cuja função é receber instruções de outras partes do programa ou sistema, a fim de desempenhar funções ou informar acerca dos resultados de outras funções ou operações já cumpridas ${ }^{54}$.

O "objecto-tipo" de alto nível confere, assim, uma espécie de matriz aos "objectos" que podem ser programados numa "linguagem orientada para o objecto" 55.

\footnotetext{
${ }^{52}$ Lance D. REICH, "One Skill in the Art in Software ...," 2003, cit., p. 52.

${ }^{53}$ V.g., a modularidade, a qual constitui uma espécie de compartimentação dos diferentes componentes de um "programa orientado para o objecto": os objectos abstractos e os processos associados são divididos em módulos, quais segmentos de programa, tornando fácil averiguar a localização de funções e os objectos específicos adentro das notações do programa - Grady BLOOCH, Object-Oriented Analysis and Design, Reading, Massachusetts, etc., Addison-Wesley Longmann Inc., 1994, p. 54; ou, noutro exemplo, a encapsulação, que respeita à apresentação de representações dos "objectos" capaz de esconder certas características ou detalhes desses "objectos"; ou, ainda, o polimorfismo, segundo o qual as novas representações dos "objectos" são subsumíveis, pelo operar do sistema, a variações de representações preexistentes; ou, ainda, o polimorfismo, segundo o qual as novas representações dos "objectos" são subsumíveis, pelo operar do sistema, a variações de representações preexistentes - Lance D. REICH, "One of Skill in the Art ...", 2003, cit., p. 52.

${ }^{54}$ Keith Beresford, Patenting Software Under the European Patent Convention, London, Sweet \& Maxwell, 2000, p. 35.

${ }^{55}$ Lance D. REICH, "One of the Skill in the Art ...", 2003, cit., p. 52; Fran K. A. KoCH, "Begründung und Grenzen des urheberrechtlichen Schutzes objektorientierter Software", in: GRUR, 2000, p. 191 s., p. 192; Andrew CHRISTIE, "Designing Appropriate Protection for Computer Programs", in: EIPR, 1994, p. 486 s., pp. 491-493; Stanley LAI, The Copyright Protection of Computer Software in the United Kingdom, Oxford, Portland, Oregon, Hart Publishing, 2000, p. 203.
} 
Deste modo, a criação de um novo sistema informático ou de um programa de computador envolve, invariavelmente, a criação de "objectos modulares" através de generalizações dos elementos funcionais pertencentes ao "sector do problema" a que o sistema informático (ou o programa) é suposto dirigir-se ${ }^{56}$. Finalmente, as relações de abstracção surpreendíveis neste "paradigma orientado para o objecto" são actualmente representadas através de um método designado por Unified Modeling Language (UML) ${ }^{57}$.

Donde, é legítimo supor que o perito na especialidade não pode desconhecer estas formas de organização dos sistemas informáticos, visto que somente dessa maneira poderá escrever as instruções, vale dizer, os códigos dos objectos e das etapas que o sistema informático implica.

A mais destas linguagens de programação, o engenheiro informático não deverá desconhecer os parâmetros físicos das máquinas (hardware) onde o programa ou o sistema informático são executados, tais como a velocidade de processamento de dados, a capacidade das memórias, as capacidades de ligação em rede etc., na medida em que quanto maior for este conhecimento melhor será a concatenação das estruturas de dados que ao programa cabe processar ${ }^{58}$. Neste sentido, o problema do nível inventivo dos sistemas informáticos para jogar, simultaneamente, vários jogos de casino (em linha) radica no acervo de informações cuja disponibilidade aproveita ao programador, tendo

\footnotetext{
${ }^{56}$ Isto é alcançado por meio da concepção de ligações (links) associativas (por agregação (id est, tipos de associação que especificam as relações entre o todo e a parte de entre um conjunto de partes componentes do sistema), composição (id est, agregações de elementos, que, de entre as partes componentes ou estruturas funcionais do sistema, partilha constrangimentos iguais ou idênticos) ou generalização (as quais determina, as relações taxonómicas (v.g., classe/ordem/família/género/espécie) entre "objectos" de cada tipo, representando o processo de abstraç̧ão e os "objectos" criados a partir do "objecto tipo", por meio da concepção de um sistema informático executável.

${ }^{57}$ Trata-se de um método de notação e de representação que, por exemplo, utiliza "gráficos de classe" (dirigidos às relações semânticas das "classes de objectos" que, do ponto de vista estático, constituem o sistema) "gráficos de cabaz" (os quais evidenciam os conjuntos de "classes de objectos" e a sua interdependência), "gráficos de actividade" (os quais descrevem o acervo de actividades e os níveis de execução do programa, fornecendo informações constantes), "gráficos de sequência" (os quais revelam as interacções e os comportamentos de "objectos" em cada situação a partir do fluir de mensagens identificadas) e gráficos de plataforma (que servem para adequar a topologia do computador onde o programa é executado) - Lance D. REICH, “One of the Skill in the Art ...”, 2003, cit., p. 52, nota 28.

${ }^{58}$ Keith Beresford, Patenting Software Under the European Patent Convention, 2000, cit., pp. 33-34.
} 
em vista a concepção de programas ou de sistemas informáticos de processamento de dados em função de um "sector do problema" exactamente plasmado no quadro da recepção e emissão de informações respeitantes às apostas efectuadas pelos jogadores e, outrossim, de pagamentos a realizar em linha.

As reivindicações de programas e sistemas informáticos desta natureza incidem em programas ou sistemas destinados ao acesso, ao processamento de dados e à utilização de vários tipos de periféricos (v.g., botões de controlo, dispositivos de baralhar cartas, visores tácteis, dispositivos de captação de imagens do distribuidor de cartas e de captação de imagens em tempo real ou em directo etc.), que não em tecnologias que visam o aperfeiçoamento da execução em linha de tais tarefas (v.g., maior rapidez, menores custos de energia etc.).

Dizer isto é dizer que a pessoa em referência (a pessoa em que se corporiza o perito na especialidade) integra o acervo de especialistas da disciplina ou do sector de actividade económica onde se coloca o problema técnico objectivo a resolver. E esse problema é, quanto a nós, e como já sustentámos, apenas um problema atinente à construção de programas ou sistemas informáticos e à ligação de periféricos (já conhecidos, há muito, no estado da técnica) adequados ao armazenamento, transmissão e visualização, em directo (ou em tempo real) de informações relacionados com apostas realizadas electronicamente por jogadores de jogos de casino.

Ora, é de supor que este perito na especialidade desfruta de alguns conhecimentos em sede jogos de casino e que, desta maneira, deverá ter adquirido um conhecimento básico do estado da técnica em matéria de armazenamento, registo, transmissão e recepção de informações, em tempo real, sobre apostas simultâneas em vários jogos. Pelo que a este perito não é inacessível a aplicação da tecnologia existente em sede da já referida Unified Modeling Language, para o efeito de conceber um sistema de acesso, transmissão, registo, recepção e processamento de informações sobre apostas efectuadas simultaneamente em vários tipos de jogos. Pois, sendo este o "sector do problema", ele apenas terá que, em princípio, convocar a tecnologia já existente em matéria de concepção, implementação e manutenção de sistemas informáticos que possam cumprir tais tarefas no domínio do exercício desta actividade económica. 
Nesta ordem de ideias, uma larga maioria de invenções de programas de computador e sistemas informáticos por meio da utilização e manipulação de periféricos e outros suportes corpóreos limita-se a adaptar os "trilhos tecnológicos" e a "arquitectura" dos programas e sistemas já divulgados.

Vale isto por dizer que é concebível a conclusão de harmonia com a qual há o sério risco de uma considerável fatia das invenções que implicam programas de computador e sistemas informáticos providos de periféricos corpóreos utilizados na indústria do jogo não desfrutarem de actividade inventiva ${ }^{59}$.

$\mathrm{Na}$ verdade, da exigência, nos ordenamentos europeus (e português) de estas invenções exibirem efeitos técnicos e tecnicidade (id est, manipulação humanamente controlável das forças da Natureza, in casu, da electricidade, do electromagnetismo e da mecânica), para além das normas interacções entre o programa e as máquinas, decorre a consequência (não raro, fatal) de a actividade inventiva de tais programas e sistemas informáticos poder ser seriamente posta em causa ${ }^{60}{ }_{-}^{61}$.

\footnotetext{
${ }^{59}$ Assim, tb., em geral, Reto HiLty/ Christophe GeIGER, "Patenting Software? A Judicial and SocioEconomics Analysis", in: EIPR, 2005, p. 615 e ss., pp. 634-635, p. 637; Frank A. KocH, "Begründung und Grenzen ...”, 2003, cit., p. 196; Lance D. ReICH, "One Skill int Art ...”, cit., p. 56; Günther SCHÖLCH, "Softwarepatent ohne Grenzen", in: GRUR, 2001, p. 16 s., p. 19; Benjamin STROM, Software Patente in Deutschland, Europa und den USA, Hamburg, Diplomatic Verlag GmbH, 2012, p. 23.

${ }^{60}$ Neste sentido, W. Cornish/D. Llewelyn/T. Aplin, Intellectual Property: Patents, Copyright, Trade Marks and Allied Rights, 7. ${ }^{\text {a }}$ ed., London, Sweet \& Maxwell, 2010, § 20-34, pp 871-872, salientando que: "For the future, the question of sufficient technical step will be dealt within under the heading of obviousness".

${ }^{61}$ Veja-se, por exemplo, a decisão T 258/03, de 21/04/2004, da Câmara Técnica de Recurso do IEP, no caso Auction method/HITACHI (consultável em https://www.epo.org/law-practice/case-lawappeals/recent/t030258ep1.html): foram depositadas reivindicações independentes a computadores programados e métodos de programação, para o efeito de propiciar a realização de leilões em linha ou leilão electrónico. Vale dizer: leilões aí onde o pregoeiro anuncia um preço mais elevado, reduzindo-o até ao momento em que recebe uma oferta, pedindo, de seguida, a manifestação de novas ofertas superiores àquela primeira. A vantagem deste sistema de leilão electrónico reside na circunstância de reduzir os tempos de espera dos potenciais oferentes. Embora este orgão jurisdicional de recurso do IEP tenha entendido que as reivindicações depositadas ostentavam suficiente carácter técnico, de jeito a poderem alicerçar uma invenção patenteável (escapando, deste modo, à proibição da patenteabilidade dos programas de computador, como tal: artigo $52 . \% / 2$ e 3 da $\mathrm{CPE}$ ), decidiu, porém, que não estava preenchido o requisito da actividade inventiva. O mesmo aconteceu, entre outras, na decisão T 368/05, de 15 de maio de 2007, no caso Integrated Account/CITIBANK, acessível em https://www.epo.org/law-practice/caselaw-appeals/recent/t050368eu1.html. Neste caso reivindicou-se um sistema de transacções financeiras em linha, o qual se achava integrado, que permitia ao cliente do banco ter acesso e subscrever, em linha, um
} 
ISSN ELETRÔNICO 2316-8080

PATENTES DE PROGRAMAS DE COMPUTADOR E DE SISTEMAS INFORMÁTICOS DE JOGOS

ELETRÔNICOS PATENTES DE MÉTODOS DE EXERCÍCIO DE ACTIVIDADES ECONÔMICAS?

\author{
De uma forma impressiva, no caso Controling Pension Benefit System/PBS \\ Partnership, a Câmara Técnica do IEP ${ }^{62}$ reafirmou que os métodos de exercer
}

conjunto de serviços financeiros. Este orgão jurisdicional justificou a falta de actividade inventiva da seguinte maneira: "These, however are all aspects of banking and marketing, basically without any relationship to the technical implementation of the system. Activities in these fields are as such excluded from patentability under the Article 52(2)(c) and (3) EPC as methods of doing business and are not capable of providing a technical contribution to the prior art. The regime of technical and thus patentable subject matter is entered only with the technical implementation on a computer system, i. e. in particular the use of a computer and communication devices to provide the required data structures (single integrated account, data fields etc.) and the technical processes to open an account via remote communication devices" — — 5, in fine, da decisão. Outrossim, na decisão T 154/04, de 15/11/2006, no caso Estimating sales activity/DUNS LICENSING ASSOCIATES (acessível em http://www.epo.org/lawpractice/case-law-appeals/recent/t040154ep1.html), foi entendido que os métodos de pesquisa de negócios estão excluídos da patenteabilidade por força do artigo $52 .^{\circ}, \mathrm{n}^{\circ} 2$, e 3 da $\mathrm{CPE}$, visto que a recolha e a avaliação de dados ou informações não implica carácter técnico a esse método de pesquisa se tais etapas ou fases (do processo) não contribuem para a solução técnica de um problema técnico.

De igual sorte, na Decisão T 1616/08, de 11/11/2009, no caso Gift order/AMAZON (consultável em https://www.epo.org/law-practice/case-law-appeals/recent/t081616eu1.html), a Câmara Técnica de Recurso do IEP entendeu que, não obstante a presença de uma invenção, esta era evidente (falta de actividade inventiva). Com efeito, o problema técnico consistia na identificação exacta da morada dos dados da ordem de aquisição do produto. Ora, a invenção que implicava um programa de computador, pressupunha perguntar essa morada, circunstância, esta, que traduz uma etapa de natureza não técnica; de igual modo, a ideia de um vendedor contactar o destinatário, em vez do adquirente, foi considerada como não técnica. Pois, nas palavras deste orgão jurisdictional: "Technical is therefore only the computer system itself and the means for communicating with the recipient, namely e-mail. But these technical means were well known at the priority date, and the invention simply uses them in a straightforward, conventional manner". Vale dizer: não é suficiente para satisfazer todos os requisitos de patenteabilidade a circunstância de a execução da alegada invenção implicar a utilização convencional de meios informáticos, por isso mesmo meios bem conhecidos do estado da técnica na data da prioridade.

${ }^{62}$ Decisão T 0935/95, de 8/9/2000, in: Official Journal of the European Patent Office, 2001, p. 441 s., p. 450 acessível em http://legal.european-patent-office.org/dg3/biblio/t950931 eu1.htm = http://www.epo.org/law-practice/case-law-appeals/recent/t950931ex1.html.

Neste caso, o requerente da patente mencionou vários elementos corpóreos de natureza técnica (os componentes corpóreos destinados ao processamento de dados nos computadores e sistemas ou redes informáticas). Todavia, este orgão jurisdicional de recurso do IEP entendeu que: "All the features of this claim are steps of processing and producing information having purely administrative, actuarial and/or financial character. Processing and producing such information are typical steps of business and economic methods", pelo que, a invenção, tal como fora reivindicada, “... does not go beyond a method of doing business as such and, therefore, is excluded from patentability under Article 52(2)(c) in combination with Article 52(3) EPC; the claim does not define an invention within the meaning of Article 52(1) EPC”. Ademais, a utilização, nas reivindicações, de meios técnicos, tendo em vista propósitos não técnicos ou o processamento de informações de natureza não técnica “... does not necessarily confer technical character to any such individual steps of use or to the method as a whole: in fact, any activity in 
actividades económicas "como tais" não são patenteáveis, ainda que sejam providos de elementos técnicos adicionais, já que essa adjunção não confere efeito técnico (ou natureza técnica: technical character) a um método não patenteável.

Mesmo nos E.U.A. - aí onde nunca foi reconhecida a exclusão da patenteabilidade das invenções com base em categorias ou espécies pré-determinadas, tais como os métodos de exercer actividades económicas (business method patents) tem sido aplicado, nos últimos anos, um maior rigorismo na admissibilidade da tutela por direito de patente das invenções de programas de computador (ou que implicam programas de computador) logradas neste último sector económico. De facto, desde o nível máximo de admissão da tutela destas alegadas invenções, no caso State Street Bank \& Trust Company v. Signature Financial Group ${ }^{63}$-, aí onde o Tribunal de recurso admitiu a patenteabilidade de qualquer invenção susceptível de produzir "a useful, concrete and tangible result" ${ }^{64}$ —, temos assistido, salvo a excepção constituída pelo caso $A T \& T$ v. Excel Communications ${ }^{65}$, a severas restrições no domínio da patenteabilidade de invenções que implicam programas de computador, conquanto no domínio dos métodos de fazer negócios.

O culminar desta via restritiva surpreende-se no caso Bilski v. Kappos ${ }^{66}$, onde o Supremo Tribunal dos E.U.A., concordando com o Federal Circuit (ao aplicar o denominado machine-or-transformation test, já usado no passado em outros

the non-technical branches of human culture involves physical entities and uses, to a greater or lesser extent, technical means" — — 3 desta decisão.

${ }^{63} 149$ Federal Supplement, third series, p. 368 s., pp. 373-77 (tirado no Federal Circuit 1998): estava em causa um sistema de processamento de dados para monitorizar e registrar fluxos de informações financeiras (in casu, destinada ao cálculo de lucros e ganhos em operações financeiras), por meio de programas de computador.

${ }^{64}$ Tb. Já assim no caso In re Alappat, decidido no Federal Circuit, em 1994 (33 Federal Supplement, third series, p. 1526 s., pp. 1544-1545), segundo o qual o programa de software origina uma nova máquina quando é executada num computador, uma vez que um computador "normal” enquanto idóneo a executar quaisquer tarefas (general purpose computer) torna-se num computador dirigido a um propósito específico (special purpose computer).

${ }^{65} 172$ Federal Supplement, third series tirado no Federal Circuit, em 1999, p. 1352 s., p. 1354.

${ }^{66} 561$ US, 130 S. Ct 3218, de 2010. Cfr. um comentário crítico a este acórdão em R. H. STERN, "Bilski: A «Flipped»Vote and then a Damp Squib”, in: EIPR, 2011, p. 115 s. 
ISSN ELETRÔNICO 2316-8080

PATENTES DE PROGRAMAS DE COMPUTADOR E DE SISTEMAS INFORMÁTICOS DE JOGOS

ELETRÔNICOS PATENTES DE MÉTODOS DE EXERCÍCIO DE ACTIVIDADES ECONÔMICAS?

domínios ${ }^{67}$ ) decidiu que as reivindicações (num quadro geral de reivindicações relativas a invenções que não envolvessem a manipulação ou a transformação de materiais corpóreos ou a alteração de estados físicos ou químicos) não continham limitações a específicas máquinas ou aparatos corpóreos, de forma a evitar que as ideias e os princípios abstractos possam ser monopolizados pelos titulares destas patentes. Pois, para esta nova doutrina a execução do programa de software deve ligar-se a um concreto aparato corpóreo ("consisting of parts, or of certain devices and combination of devices ..."), no sentido de permitir a transformação, química ou física, de objectos ou substâncias ("a chemical or physical transformation of physical objects or substances"), designadamente uma transformação de dados ou elementos informativos num visor da máquina, que não apenas a mera recolha e organização de tais elementos informativos. Os dados ou elementos objecto de processamento devem representar objectos corpóreos ${ }^{68}$. E, outrossim, no caso Alice Corp PTY Ldt v. CLS Bank International, de 19/6/2014, deste Supremo ${ }^{69}$.

Por último, temos a recente decisão do Federal Circuit, de 5/09/2013, no caso Accenture Global Services GmbH v. Guidewire Software Inc ${ }^{70}$, cuja patente em crise reivindicara um sistema informático respeitante à gestão de uma base de dados de informações sobre seguros. O Federal Circuit, sob a batuta do Juiz LOURIE, mantendo a decisão da 1. instância (no caso, tirada no District Court for the District of Delaware), entendeu que "the system claim essentially implemented the process of the method claim on a general purpose computer" — o itálico é meu — e que as expressões

\footnotetext{
${ }^{67}$ Cfr. o caso Gottschalk v. Benson e outros 40 US 63, decidido em 20/11/1972, pelo Supremo Tribunal dos E.U.A., segundo o qual um "method for converting numerical information from binary-coded decimal numbers into pure binary numbers, for use in programming conventional general-purpose digital computers is merely a series of mathematical calculations or mental steps and does not constitute a patentable "process" within the meaning of the Patent Act, 35 U.S.C. 100 (b)".

${ }^{68}$ Para a crítica negativa deste teste, cfr. Craig A. NARD, The Law of Patents, 3. ${ }^{a}$ ed., cit., 2014, pp. 228231; Janice M. Muller, Patent Law, 4. ${ }^{a}$ ed., Wolters Kluwer, 2013, pp. 356-366.

${ }^{69} 573$ U.S, 134 S. Ct.2347 = http://www.supremecourt.gov/opinions/13pdf/13-298_7lh8.pdf. Curava-se de um programa que intermediava a conta corrente do fornecedor e do adquirente de produtos. Cfr. Richard H. STERN, "Alice v CLS Bank: US Business Method and Software Patents Marching Towards Oblivion?”, in: EIPR, 2014, p. 619, ss., p. 623 ss.

${ }^{70}$ In: http://www.cafc.uscourts.gov/images/stories/opinions-orders/11-1486.Opinion.9-3-2013.1.PDF.
} 
limitativas, constantes das reivindicações, relacionadas com o hardware não tinham significado. Na verdade, pese embora as reivindicações tenham feito referência, por exemplo, a servidores, base de dados para realizar tarefas e aos demais componentes referidos na descrição, o Tribunal entendeu que estes componentes eram "merely composed of generic computer components that would be present in any general purpose computer". De modo que o objecto da invenção foi subsumido à realidade não patenteável prevista na Secção 101 do Título 35 do United States Code (no caso, abstract ideas). Segundo esta Seção, "Whoever invents or discovers any new and useful process, machine, manufacture of composition of matter ... may obtain a patent therefore, subject to the conditions and requirements of this title".

No case law estadunidense é assim relevante indagar se a execução do programa causa alterações físicas, químicas, electromagnéticas em outros objectos ou substâncias. É assim essencial que a execução do programa cause um efeito ou resultado fisicamente tangível, diferentemente da metódica emergente do IEP, aí onde se exige a presença de um contributo técnico. Pois, o adicionar, nas reivindicações, elementos corpóreos constitutivos de um sistema informático (v.g., fios, periféricos, etc.) a ideias não "transforma" estas ideias (e o valor abstractizante que elas supõem) numa máquina ou em outro aparato corpóreo ${ }^{71}$.

Daqui resulta que a mera implementação técnica de realidades não patenteáveis (métodos de fazer negócios "como tais" e programas de computador "como tais") não confere patenteabilidade a essas mesmas realidades. Conquanto o problema em causa seja analisado do ponto de vista da presença (ou ausência) de actividade inventiva, fazse mister analisar a forma como é implementado um método (de exercício de

\footnotetext{
${ }^{71}$ O panorama no Brasil é tributário do estadunidense. As directrizes para exame do INPI brasileiro (www.inpi.gov.br) impedem a patenteabilidade de métodos de fazer negócios, conquanto permitam lograr o aumento de vendas ou da produtividade. E isto é assim mesmo que o método de fazer negócios seja reivindicado como sistema, incluindo os métodos financeiros (p. ex., um método de compras on line). Outrossim, de dirá da implementação na internet de métodos desta natureza ou da sua automação que importa a presença de seres humanos. O umbral da patenteabilidade parece residir na circunstância de $\mathrm{o}$ método (não preexistente no estado da técnica) poder ser cindido dos elementos financeiros/contabilísticos/comerciais, especialmente se for reivindicada a máquina (o produto) enquanto solução técnicas desligada do aspecto financeiro (p. ex., novas máquinas ATM ou um método de criptografia para efectuar operações bancárias on line com acréscimo de segurança). Sobre isto, cfr. Marcos Wachowicz, Propriedade Intelectual do Software \& Revolução da Tecnologia da Informação, Curitiba, Juruá Editora, reimpressão, 2010, pp. 188-193.
} 
actividades económicas, no domínio do jogo, ou um programa de computador) excluído à partida do universo das realidades patenteáveis ${ }^{72}$.

Assim, a actividade inventiva não pode apenas ser alicerçada na implementação das etapas ou fases do método de exercício de actividades económicas, de jogo ou do programa de computador ${ }^{73}$.

\section{O alcance do ius prohibendi nas patentes de programas de computador e a importância das reivindicações (independentes)}

Portugal, tal como a larga maioria dos restantes países europeus, adopta um sistema de reivindicação central constituído por um preâmbulo e por uma parte caracterizante, na qual são expostas as características técnicas que definem a extensão da proteção requerida. Esta metodologia é originária do ordenamento jurídico alemão, austríaco e suíço, tendo sido acolhida no IEP e em Portugal.

Atente-se no disposto no artigo $84 .^{\circ}$ da CPE, na Regra n. 29 do Regulamento de Execução da CPE, no artigo $62^{\circ}{ }^{\circ}$ n. ${ }^{\circ}$ 3, alínea $a$ ) e $b$ ), do CPI português. Não se

\footnotetext{
${ }^{72}$ S. STERCKX/J. Cockbain, Exclusions from Patentability -How Far Has the European Patent Office Eroded Boundaries?, 2012, cit., pp. 83-84.

${ }^{73}$ Veja-se a Decisão T 1543/06, de 29/6/2007, da Câmara Técnica de Recurso do IEP, no citado caso Game machine/GAMEACCOUNT, § 5.1. Um pouco adiante, este orgão jurisdicional logo afirma que: "Implementation is by way of a monitor and processor of what is effectively a computer system, which in most of the claims also has an input device. Computer implementation of games is per se manifestly known. This fact allows the Board to identify the skilled person as a gaming software engineer, skilled in the field of computer games" - (§ 5.2.) o itálico é meu. No mais, este Tribunal confessou não ser possível identificar quaisquer outros efeitos senão aqueles inerentes às "regras do jogo" (game rules), bem como todos os demais relacionados com a execução de funções por um computador provido de um processador e um display. Além de que não identificou qualquer efeito sinergético entre as "regras do jogo" a e implementação técnica do programa, já que as reivindicações e a descrição não forneciam quaisquer detalhes acerca da forma exacta pela qual a unidade central de processamento se achava configurada para desempenhar tais tarefas (§ 5.4.). Isto dito não obstante o requerente da patente tenha justificado um alegado contributo técnico do seguinte modo: “... affecting the efficiency of the process of playing the game which also adds a degree of skill, predictability, sophistication and interest". O Tribunal repudiou completamente esta justificação, na medida em que ela respeita "entirely to gaming concerns and factors that may be of importance in the non-technical domain of games, and which in any case flow from the rules' central idea" (§ 5.4., in fine). Por exemplo, a informação fornecida aos jogadores não era disponibilizada nos monitores sob uma qualquer forma particular (e inventiva).
} 
esqueça, porém, que a invenção cuja proteção é peticionada deve achar-se reflectida na "parte caracterizante" 74. A 1. parte, ou "preâmbulo", sumaria os elementos essenciais conhecidos no estado da técnica; a 2. " parte (a "parte caracterizante") introduz os aspectos técnicos novos e inventivos da invenção. Neste sentido, os titulares das patentes de programas de computador em matéria de jogos de casino apenas extraem o potencial máximo dos seus exclusivos industriais se puderem inibir terceiros não autorizados da prática de actos de venda, importação, fabrico, e posse (no território português), uno actu e em combinação: dos sistemas de jogo; dos terminais, rede de terminais, das unidades de controlo $(\mathrm{CU})$, das unidades centrais de processamento para computação de apostas e historial (BCPU), das luzes sinalizadoras, monitores, impressoras para recibos, caixas para recibos, das plataformas para colocar álcool, bebidas, cinzeiros etc., dos dispositivos de vigilância, mesas de distribuição de cartas com dispositivos de visores tácteis.

Vale dizer: o exclusivo industrial terá muito menor valor merceológico se os titulares somente puderem impedir terceiros não autorizados de importar, vender, fabricar ou deter em Portugal os sistemas de jogos de casino providos de todas estas funcionalidades (corpóreas e incorpóreas). Isto porque será escasso ou diminuto o valor destas patentes se os titulares não puderem impedir a prática dos referidos actos relativamente a cada um dos múltiplos componentes (corpóreos e incorpóreos) e interfaces constitutivos destes sistemas de jogo para casinos.

Daqui decorre o seguinte: se o objecto da patente for um "sistema para jogos", compreendendo os referidos componentes, ou um "sistema de jogo" que compreende vários outros componentes corpóreos e incorpóreos, a importação para Portugal (ou o fabrico, venda ou posse em Portugal) de apenas alguns desses componentes (v.g., mesas de jogo, desprovidas dos visores; impressoras de recibo sem o servidor de pagamento;

\footnotetext{
${ }^{74}$ Por exemplo, atente-se na numa reivindicação independente de um hipotético pedido de patente respeitante a um "rato" ("mouse"), qual dispositivo periférico de um computador — o hardware — (e de execução do programa de computador: o software): "um dispositivo deslizante sem fios que permite, quando conexionado com um computador, mover o cursor, sendo que tal dispositivo é provido de um rotor na parte superior dianteira central e duas peças permeáveis à pressão, colocadas na frente do lado esquerdo e do lado direito" [preâmbulo], "caracterizado pela circunstância de existirem meios, nesse cursor, susceptiveis de reduzir a fricção entre as mãos do utilizador e esse cursor" [parte caracterizante] — as expressões que colocámos em itálico pretendem traduzir os aspectos novos e inventivos desta invenção.
} 
mesas de jogo sem o dispositivo de vigilância etc.) ou software não permite que o titular da patente proíba a prática de tais actos de índole merceológica isoladamente considerada.

O âmbito de proteção de patentes desta natureza somente abrange os componentes corpóreos e incorpóreos individualmente considerados de um sistema informático se estes forem objecto, cada um deles, de reivindicações independentes. Outrossim, em se tratando de patentes de processo, devem ser depositadas reivindicações independentes respeitantes a todas as fases, etapas ou sequências novas e inventivas do processo susceptíveis de serem executadas separadamente das restantes fases ou sequências do processo no seu conjunto, que não somente uma reivindicação independente (provida de reivindicações dependentes e eventuais reivindicações subdependentes destas últimas).

Esta é, no essencial, a insuficiência de um sistema de "reivindicação central" (central claiming), ao invés de um sistema de reivindicação periférico (peripherical claiming). Neste outro, e sem menosprezo ou infração das regras de exposição das reivindicações nos pedidos de patente que seguem aquele sistema de central claiming, o requerente da proteção, a fim de lograr uma proteção adequada e o mais extensa possível, deverá depositar tantas reivindicações independentes quantos os dispositivos corpóreos ou programas de computador (software) susceptíveis de serem comercializados, fabricados, importados para Portugal ou aqui detidos separadamente. Pois, se assim o fizer ficará livre de proibir, em sede de violação directa do direito de patente, todos aqueles actos merceológicos no território português relativamente a cada um dos componentes (corpóreos e incorpóreos) do sistema de jogo de casino.

Embora o sistema de reivindicação que também vigora em Portugal seja o do central claiming, o certo é que, para o efeito da tutela da substância inerente ao licere do direito de patente e das suas faculdades jurídicas de exigibilidade perante terceiros, deve ser utilizado (tal como no ordenamento britânico) um sistema de peripherical claiming. Paradigmático desta descontinuidade, não raras vezes desconsiderada pelos peticionantes de patentes, é a decisão do Tribunal Federal alemão de Patentes, de 
24/03/1987, no caso Rundfunkubertragunssytem ${ }^{75}$, aí onde o tribunal entendeu que o objecto da patente era o sistema de transmissão, que não os receptores per se ${ }^{76}$.

Haverá insuficiência de proteção se nos pedidos de patente não se surpreenderem reivindicações independentes dirigidas a cada um dos dispositivos corpóreos e incorpóreos constitutivos do "sistema de jogo" ou do "sistema para jogar". Com efeito, destinando-se as referidas invenções a ser usadas em sistemas ou redes informáticas, os fascículos das respectivas patentes não devem ser omissos quanto à presença de reivindicações independentes relativas aos singulares processos, sequências ou etapas executáveis nos diferentes pontos da rede ou sistema ou em específicos computadores (hardware). Outrossim, estes fascículos das referidas patentes devem incluir reivindicações independentes dirigidas aos singulares elementos corpóreos da rede informática). É assim altamente duvidoso, senão mesmo legalmente impossível, que o fornecimento (em Portugal) de mesas de jogos constitua infração directa das referidas patentes.

Se o programa for usado num sistema ou numa rede informática, o titular não desfrutará de tutela patentária se apenas depositar uma única reivindicação independente (do aparato ou dispositivo corpóreo e incorpóreo) dirigida à combinação da rede ou do sistema com os computadores (e outros interfaces corpóreos de intercomunicabilidade de processamento de informações) ${ }^{77}$. Não haverá, por certo,

\footnotetext{
${ }^{75} 20 \mathrm{~W}$ (pat) 8/99, in: GRUR, 1999, p. 99. A patente consistia num sistema de rádio VHF, por meio do qual os rádios dos automóveis se conectam automaticamente a uma estação de rádio, que informa os condutores dos problemas existentes nas estradas e vias públicas. A implementação deste sistema implica a presença de um transmissor de rádio, que transmite uma nova forma de sinal sempre que é emitido uma informação sobre o estado do trânsito num certo local, bem como inclui um receptor radiofónico que possui um sistema de detecção do primeiro sinal de rádio, pelo qual liga automaticamente à estação de radiodifusão em causa. Todavia, dado que apenas fora formulada uma reivindicação independente dirigida a um sistema estereofónico de transmissão VHF, no qual "o transmissor de VHF é modulado ..., caracterizado por ..." - e fora omitida a junção de uma reivindicação independente ao receptor per se , o réu foi absolvido do pedido de infração (directa) da patente, já que apenas se provou que vendia receptores e não transmissores.

${ }^{76}$ Obviamente, que esta reivindicação havia sido redigida ao abrigo do sistema do central claiming. Isto não obstava, todavia, a que (já então) o requerente da patente tivesse depositado reivindicações independentes atinentes aos transmissores per se e aos receptores per se, tal como é prática nos sistemas jurídicos que privilegiam o peripherical claiming como modus operandi.

${ }^{77}$ K. Beresford, Patenting Software Under the European Patent Convention, London, Sweet \& Maxwell, 2000, p. 87.
} 
ISSN ELETRÔNICO 2316-8080

PATENTES DE PROGRAMAS DE COMPUTADOR E DE SISTEMAS INFORMÁTICOS DE JOGOS

ELETRÔNICOS PATENTES DE MÉTODOS DE EXERCÍCIO DE ACTIVIDADES ECONÔMICAS?

infração directa da patente se e quando um terceiro não autorizado adquirir ou vender, em Portugal, alguns dos terminais de jogo, com exclusão, por exemplo, das unidades de controlo $(\mathrm{CU})$ ou das unidades centrais de processamento para registos de computação e historial das apostas (BCPU). Poderá existir infração indirecta da patente ${ }^{78}$, mas não infração directa.

Desta maneira, a necessária presença de um contributo técnico nas invenções de programas de computador e sistemas informáticos implica que o requerente da proteção não pode correr o risco de omitir a indicação completa dos efeitos ou resultados técnicos. Na verdade, far-se-á mister que essa indicação abranja a globalidade do sistema, cuja descrição e existência é suposto verificar-se para que a invenção possa funcionar aos olhos do perito na especialidade. Não se esqueça que em época anterior ao movimento doutrinal e jurisprudencial protagonista da contemporânea interpretação restritiva da proibição (da patenteabilidade das invenções de programas de computador) contida no . $^{\circ} 2$ do artigo $52 .^{\circ}$ da $\mathrm{CPC}$, os programas de computador não podiam constituir, por si só, objecto de patente: a proteção (indirecta) que a lei lhes oferecia apenas funcionava se e quando estes programas integrassem um dispositivo técnico mais vasto materializado em outros processos ou em máquinas diversas daquelas em que o programa era susceptível de ser directamente executado.

Mas a tutela assim conferida a tais alegadas invenções (que implicam programas e sistemas informáticos) não é uma tutela otimizante quando é alicerçada em reivindicações desta natureza. Pois, não permite que o titular possa, sem controvérsia, reagir directamente contra actos não autorizados de reprodução e venda de componentes do sistema (v.g., suportes tangíveis programados, o código fornecido electronicamente, através de um sinal na Internet ou em suporte papel). Nestes casos, a única possibilidade de reacção do titular deste tipo de patentes radica na convocação, quando

\footnotetext{
${ }^{78} \mathrm{~A}$ infração indirecta da patente é o ilícito que se verifica quando um terceiro não autorizado pelo titular da patente fornecer ou disponibilizar a qualquer pessoa que não tenha o direito de explorar a invenção patenteada, os meios para utilizar, nesse território, a referida invenção no que se refere a um seu elemento essencial, caso o terceiro tenha ou deva ter conhecimento de que tais meios são adequados e destinados a essa utilização - p. ex., artigo 26. ${ }^{\circ}$, n. ${ }^{\circ}$ 1, do Acordo Relativo ao Tribunal Unificado de Patentes, no quadro da denominada patente europeia com efeito unitário, aprovado pela Resolução da Assembleia da República [de Portugal], n. ${ }^{\circ}$ 108/2015, in: Diário da República, I Série, n. ${ }^{\circ} 152$, de 6/08/2015, acessível em https://dre.pt/application/file/69958596.
} 
admitida no ordenamento jurídico do Estado em cujo território ocorreu a alegada infração, dos mecanismos jurídicos que previnem a denominada contrafacção ou violação indirecta do direito de patente. Isto sem que o programa (ou sistema informático) ou os demais componentes (corpóreos e incorpóreos) desse sistema constituam um meio essencial e necessário para realizar a invenção protegida. E, mesmo assim, a tutela contra esses actos de violação indirecta do direito de patente não atinge os actos de fabrico (salvo se estes forem subsumíveis a actos preparatórios ou preordenados à ulterior e imediata colocação no mercado), nem as actividades de exportação destes componentes do sistema informático.

Donde, mesmo que o programa de computador constitua o único elemento dotado de novidade e actividade inventiva, a sua reprodução e colocação no mercado do Estado ou território que atribuiu proteção separadamente dos restantes elementos que caracterizam a invenção não constitui uma violação directa do direito de patente, se e quando esse programa de computador e/ou respectivos componentes (corpóreos e incorpóreos) não tiverem sido objecto de reivindicações independentes (posto que autónomas e autosuficientes) ${ }^{79}$. A utilização de reivindicações independentes precipitadas sobre todos os componentes (corpóreos, designadamente, CD-ROM pendrive, e incorpóreos) por meio dos quais o programa de computador pode ser executado constitui, deste modo, o expediente por via do qual pode ser sancionada uma eventual violação directa do direito de patente. Além disso, esta forma de reivindicar permite, igualmente, superar eventuais objecções fundadas no facto de o programa não revelar um qualquer "contributo" ou "efeito" de natureza técnica, a ponto de se tornar uma realidade não patenteável, ao artigo do disposto no artigo $52 .^{\circ},{ }^{\circ} .^{\circ}$, alínea $d$ ), in fine, do CPI (veja-se a expressão “como tais”).

A proibição da patenteabilidade dos programas de computador "como tais", sem qualquer contributo técnico (por não se tratar, assim, de invenções), pode assim ser superada, também no ordenamento jurídico português, se o requerente tiver reivindicado o programa por meio de reivindicações independentes, fora ou para além do conceito inventivo geral ou do sistema em que ele se insere ou realiza o efeito técnico que a sua execução desencadeia nos computadores ou redes de computadores. A venda, em

\footnotetext{
${ }^{79}$ J. P. REMÉDIO MARQUES, Biotecnologia(s) e Propriedade Intelectual, vol. II, 2007, cit., pp. 742-744.
} 
ISSN ELETRÔNICO 2316-8080

PATENTES DE PROGRAMAS DE COMPUTADOR E DE SISTEMAS INFORMÁTICOS DE JOGOS

ELETRÔNICOS PATENTES DE MÉTODOS DE EXERCÍCIO DE ACTIVIDADES ECONÔMICAS?

Portugal, de alguns dos terminais susceptíveis de executar as apostas em linha multijogos não constituirá infração directa das referidas patentes se for desacompanhada, neste exemplo, da venda das unidades de controlo e das unidades centrais de processamento ou, noutro exemplo, dos programas de software para executarem qualquer função da unidade de controlo ou da unidade central de processamento $(\mathrm{CU})$ para registos de computação e historial das apostas (BCPU). Haveria, isso sim, infração indirecta da patente_se — pressupondo a venda de alguns daqueles componentes do sistema ou da rede — as unidades de processamento, os terminais e os demais elementos corpóreos estivessem localizados em Portugal ${ }^{80}$.

\section{Concretização}

Daí que, quanto muito, a "oferta" de terminais de jogo ou, em alternativa, de dispositivos corpóreos mencionados em reivindicações relativas a sistemas de jogos protegido por patente (de processo, produto ou uso) apenas poderá ser qualificada como infração indirecta.

Estas máquinas e demais periféricos ligados ao exercício da actividade económica privada de jogo, traduzida no fabrico, introdução no comércio português, importação, etc., não se confundem com a invenção patenteada cuja utilização seja feita por terceiro não autorizado.

Estas alienações de terminais e/ou de dispositivos corpóreos (periféricos) permitem ou facilitam a comercialização (ou a "oferta") do objecto da patente. É indesmentível. Podem elas ser assim qualificadas como "meios relativos a elementos essenciais de uma invenção". Porém, como referi, este ilícito traduzido no

\footnotetext{
${ }^{80}$ Todavia, em Portugal, mesmo após a transposição para o CPI da Directiva n. ${ }^{\circ}$ 2004/48/CE, relativa ao respeito dos direitos de propriedade intelectual, este ilícito não se encontra expressamente consagrado assim, J. P. REMÉDIO MARQUES, "Violação indirecta do direito de patente - Análise comparativa: direito português, direito estrangeiro e jurisprudência", in: O Direito, ano $140^{\circ}$ (2008), p. 75 ss., pp. 769-775; no mesmo sentido, cfr. agora o acórdão da Relação de Lisboa, de 3/3/2015, proc. n. ${ }^{\circ}$ 1034/14.4YRLSB, em cujo sumário se lê: "o ordenamento jurídico português não consagra o ilícito da infração indirecta do direito de patente (ou CCP), contrariamente ao que se verifica em alguns Estados aderentes à Convenção sobre a Patente Europeia". Por outro lado, ainda não entrou em vigor o regime da Patente Europeia com efeito unitário, em cujo artigo $26^{\circ},{ }^{\circ} .^{\circ} 1$, como vimos (supra, nota ${ }^{\circ}{ }^{\circ} 76$ ) se estabelece este específico ilícito do direito de patentes.
} 
"fornecimento de meios relativos a elementos essenciais de uma invenção patenteada" não está previsto no direito de patente português.

\section{A tendencial insuficiência da tutela por direito de autor dos programas de computador e sistemas informáticos dos requeridos}

Pode, ademais, postular-se a questão de saber se o software cuja proteção por patente não tenha sido objecto de reivindicações independentes respeitantes a todos os componentes do sistema que possam ser alienados separadamente merece, ainda assim, a proteção pelo direito de autor. $\mathrm{Ou}$, inclusivamente, se, não podendo o programa ser objecto de patente, pode este ser tutelado pelo direito de autor. Na Europa e nos E.U.A., na década de oitenta do século passado, assistiu-se a um movimento jurisprudencial e legiferante no sentido de atribuir proteção aos programas de computador pelo direito de autor (ou um direito análogo aos direitos de autor). Todavia, a verificação de alguma relutância em estender a proteção conferida pelo direito de autor à estrutura do programa, à sequência das instruções; à sua organização interna, à apresentação dos "menus" no ecrã dos computadores, bem como a possibilidade de a generosa cláusula do fair use estadunidense ser geralmente aplicada às operações de descompilação dos programas, operações cuja (i)licitude está rigorosamente traçada no espaço jurídico da União Europeia, fez surgir a ideia (que já lavrava desde os inícios dos anos setenta do século XX), segundo a qual o direito de patente constitui, apesar de tudo, o subsistema de propriedade intelectual mais adequado para proteger esta tecnologia informacional ${ }^{81}$.

Pois bem. O interesse está em não divulgar o código-fonte, ao invés do que ocorre por ocasião do depósito (e publicação) do pedido de patente ${ }^{82}$. Se é verdade que os programas de computador "como tais" (isto é, sem qualquer contributo técnico) podem ser tutelados pelo direito autoral, não é menos verdade que esta proteção pelo

\footnotetext{
${ }^{81}$ Crítico, entre muitos, acerca da adequação do direito de patente, F. POLLAUD-DuLIAN, “Adéquation ou inadéquation de la protection du logicile par brevet", in: La propriété intellectuelle en question(s): regards croisés européens. Colloque, 16-17 juin 2005, Paris, Litec, 2006, p. 183 ss.

${ }^{82}$ E beneficiar de uma proteção durante 70 anos após a morte do criador intelectual ou da primeira publicação ou divulgação ao público do programa, se, neste último caso, o titular não for o criador (art. 36. ${ }^{\circ}$ do CDA, na redação do Decreto-Lei n. ${ }^{\circ} 334 / 97$, de 27 de novembro).
} 
ISSN ELETRÔNICO 2316-8080

PATENTES DE PROGRAMAS DE COMPUTADOR E DE SISTEMAS INFORMÁTICOS DE JOGOS

ELETRÔNICOS PATENTES DE MÉTODOS DE EXERCÍCIO DE ACTIVIDADES ECONÔMICAS?

direito de autor não só não se estende aos actos de utilização da concreta aplicação da solução técnica (obtida através da execução do programa) ${ }^{83}$.

A dimensão funcional dos programas não é protegida, já que esta respeita a elementos não expressivos do programa.

O objecto legal de proteção é, na verdade, apenas a expressão do programa. $\mathrm{O}$ regime jurídico português não deixa dúvidas nesse sentido, dispondo inequivocamente que as ideias, os processos, os sistemas, os métodos operacionais, os conceitos, os princípios que estão na base de qualquer elemento do programa não são, por si só e enquanto tais, protegidos pelo direito de autor (artigo $1 .^{\circ}$, n. $^{\circ} 2$, do CDA). A lei apenas consente que o titular do direito autoral respeitante ao programa informático reaja contra terceiros perante a reprodução ou imitação ${ }^{1}$ (id est, de elementos não literais) da "arquitectura", da sequência e da organização do programa, da expressão dos algoritmos em diagramas e fluxogramas, em termos da forma de expressão do fluir das informações objecto de processamento ${ }^{84}$ — incluindo a reprodução, conquanto não literal, do material de concepção ou preparatório do programa (p. ex., gráficos de circulação e flow-charts) ${ }^{85}$. Em rigor, o titular dispõe, em Portugal, do poder de proibir

\footnotetext{
${ }^{83}$ Que o mesmo é dizer que o titular desta proteção fica impedido de reagir contra a comercialização de todos os componentes do sistema informático -, como também não desfruta de qualquer protecção relativa ao próprio algoritmo ou dos princípios (matemáticos) que estão na génese de qualquer um dos elementos do programa - J. P. RemÉDIO MARQUES, Biotecnologia(s) e Propriedade Intelectual, vol. I, 2007, cit., p. 137, nota 265; José Alberto VIeIRA, A Proteção dos Programas de Computador pelo Direito de Autor, Lisboa, Lex, 2005, p. 285, pp. 287-288.

${ }^{84}$ C. DESCHAMPS, "Patenting Computer-related Inventions in the US and in Europe ...", 2011, cit., p. 106

${ }^{85}$ A. DiAs PEREIRA, Direitos de Autor e Liberdade de Informação, Coimbra, Almedina, 2008, pp. 397398. Cfr. o artigo $166 .^{\circ}$, n. $^{\circ} 1$, do regime jurídico do direito de autor e direitos conexos de Macau, aprovado pelo Decreto-Lei n. ${ }^{\circ}$ 43/99/M, de 16 de agosto, segundo o qual: "A protecção atribuída aos programas de computador incide sobre a sua expressão e não prejudica a liberdade das ideias e dos princípios que estão na base de qualquer elemento do programa, como sejam a lógica, os algoritmos ou a linguagem de programação em que o programa foi escrito" - o itálico é meu. O que se coaduna com o artigo $2 .^{\circ}$, n. ${ }^{\circ}$, alínea $a$ ), do mesmo regime jurídico, na redaç̧ão da Lei $.^{\circ}{ }^{\circ} 5 / 2012$, de 10 de abril, do mesmo regime jurídico determina que são, nomeadamente, obras protegidas, contanto que sejam originais: "Os textos de carácter literário, jornalístico, científico ou qualquer outro, incluindo os programas de computador" - o itálico é meu. Idem, no direito português: art. $2 .^{\circ}, \mathrm{n}^{\circ}{ }^{\circ}$, do Decreto-Lei n. ${ }^{\circ} 252 / 94$, de 20 de outubro, segundo o qual a tutela dos programas de computador pelo direito de autor "não prejudica a liberdade das ideias e dos princípios que estão na base de qualquer elemento do programa ou da sua interoperabilidade, como a lógica, os algoritmos ou a linguagem de programação". No mesmo sentido navega a doutrina brasileira: Marcos WACHOWICZ, Propriedade Intelectual do
} 
a reprodução (permanente ou transitória) ${ }^{86}$ da expressão do programa ${ }^{87}$, controlando a cópia de qualquer extensão dessa expressão ${ }^{88}{ }_{-}^{89}$.

Atenta esta ubíqua forma da proteção autoral dos programas de computador (rectius, face a esta proteção da expressão do programa, que não das funções desempenhadas ou dos resultados que ele atinge) é, ainda assim, particularmente difícil

Software, 2010, cit., pp. 78-79, segundo o qual «é a expressão de uma solução que merece tutela pelo direito autoral e não a solução encontrada, ou a sua idéia primitiva», de modo que «a finalidade do programa de computador, sua utilidade e a funcionalidade que lhe agregam valoração econômica estão ligadas ao tratamento da informação»; Denis BORges BARBosA, Propriedade Intelectual. Direitos Autorais. Direitos Conexos e Software, Rio de Janeiro, Lumen Juris, 2003, p. 145; Denis BorgeS BARBosa, Direito de Autor - Questões fundamentais de direito de autor, Rio de Janeiro, Lumen Juris, 2013, p. 9; Denis Borges Barbosa, Tratado da Propriedade Intelectual, Tomo III, A Proteção do Software. Do sigilo dos Testes para Registro de Comercialização. Topografias de Circuitos Integrados, Rio de Janeiro, Lumen Juris, 2010, p. 1901, que afirma: «O programa, no exercício da sua funcionalidade e satisfazendo a sua destinação necessária, pode resultar em duas formas de resultado que têm pertinência para a análise de Propriedade Intelectual: efeitos expressivos de qualquer natureza, como textos, imagens, sons. E efeitos técnicos que (...) podem recair no âmbito da proteção por patentes (...) Assim não existe, no atual direito, possibilidade de direitos autorais - por exemplo - sobre o resultado de um funcionamento automático de um engenho captador de imagens por satélites. Não se argumente que os comandos para direccionar a captação para um ou para outro objeto sejam, em algum grau, resultantes de decisão humana. Tal decisão, se houver, é de natureza meramente técnica, e não importa criação autora» — os itálicos são meus.

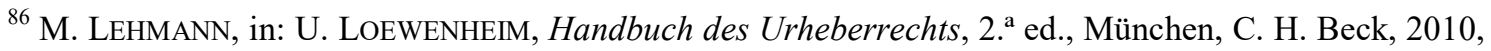
$\S 76$, pp. 1864-1865.

${ }^{87}$ Os elementos não expressivos exorbitam o âmbito de proteção reconhecido ao titular do direito de autor sobre o programa (p. ex., ideias, métodos de operação, processos, lógica, funções técnicas etc.).

${ }^{88}$ V.g., por meio de cópia directa de um programa em código objeto (maxime, armazenamento num CDROM para o disco-rígido ou para um outro "local" em linha, por exemplo, um armazenamento "em nuvem"); por meio de carregamento do programa para a memória do computador, a partir de um dispositivo periférico de memória (telemóvel, dispositivo de USB, etc.), a transmissão do programa (por meio de envio, no todo ou em parte, do local onde está armazenado, para outro local, ou seja o download e o upload do programa) enquanto conduta que faz parte do conteúdo do direito de distribuição.

${ }^{89}$ Bem como a transformação desse programa (ou a forma do mesmo) e a reprodução do programa derivado por tradução, adaptação ou outro meio, o direito de pôr em circulação originais ou cópias desse programa e o direito de locação de exemplares, o direito de comunicação ao público do programa e outros modos de exploração económica que a evolução tecnológica venha a propiciar. Qualquer concorrente que queira fabricar ou adquirir um programa de computador (ainda quando incorporado em outras máquinas) com funcionalidades equivalentes ou iguais às de um programa anteriormente protegido pode fazê-lo licitamente, já que as ideias e os princípios que servem essa funcionalidade são livres. Somente se exigirá que tais concorrentes desenvolvam uma expressão própria ou exteriorização do algoritmo. 
ISSN ELETRÔNICO 2316-8080

PATENTES DE PROGRAMAS DE COMPUTADOR E DE SISTEMAS INFORMÁTICOS DE JOGOS

ELETRÔNICOS PATENTES DE MÉTODOS DE EXERCÍCIO DE ACTIVIDADES ECONÔMICAS?

distinguir as condutas saudavelmente competitivas (e lícitas) que atingem o programa protegido daquelas outras que constituem notórias infrações ao direito autoral.

Mesmo no domínio da forma de expressão do programa, o objecto (processual) da inquirição pelo tribunal fixa-se, as mais das vezes, na análise das linhas de programação (do código fonte) ou dos demais elementos de expressão do programa, isto é, a sua estrutura, sequência e organização ${ }^{90}$, sem que, para afirmar a ilicitude, seja necessário alegar e provar a reprodução, linha a linha, ipsis verbis, das instruções ${ }^{91}$, mas, numa visão mais proteccionista do titular, demonstrar apenas uma "similitude na estrutura" (vale dizer, por exemplo, nas listagens do código fonte), ou uma utilização de partes substanciais das linhas de programação do titular, do fluxograma, mesmo que seja utilizada uma diferente linguagem de programação.

Não se esqueça que as ideias e as linguagens de programação não são, neste caso, apropriáveis. Um eventual demandado pelo titular do direito de autor, ainda quando utilize um programa que desempenha a mesma função (por exemplo, o exercício de uma actividade económica no domínio do multigaming em linha), facilmente se coloca numa "área de não infração" se, por exemplo, demonstrar que o código-fonte é diferente ou essencialmente diferente, ou que este desfruta de mais linhas de programação e, logo, um maior número de subdivisões e combinações de instruções. Que o mesmo é dizer que os elementos funcionais do programa não se situam adentro do objecto de proteção do direito de autor; objecto de proteção é apenas a expressão do programa $^{92}$.

\footnotetext{
${ }^{90}$ A. DiAs Pereira, Direitos de Autor e Liberdade de Informação, 2008, cit., pp. 401-402. Cfr., tb., sobre os testes da abstraç̧ão/filtragem/comparação, dissecação analítica e o dos elementos essenciais, J. P. REMÉDIO MARQues, Biotecnologia(s) e Propriedade Intelectual, vol. I, 2007, cit., p. 132, nota 263, com referência à jurisprudência dos E.U.A.; RUI SAAVEDRA, A Proteção Jurídica do Software e a Internet, Lisboa, Sociedade Portuguesa de Autores, Dom Quixote, 1998, pp. 131-132, nota n. 314.

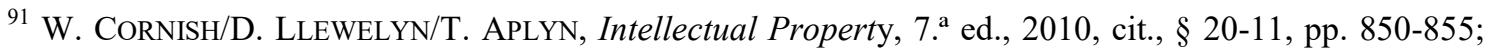
T. DREIER, in: T. DREIER/G. SCHULZE, UrhG, Urheberrechtsgesetz, Urheberrechtswahrnehmungsgesetz, Kunsturherbergesetz, Kommentar, 3. ${ }^{a}$ edição, München, C.H. Beck, 2008, § 69a, pp. 998-1000; M. LeHMANN, in: U. LOEWENHEIM, Handbuch des Urheberrechts, 2. ${ }^{a}$ ed., 2010, cit., § 76, pp. 1861-1863.

${ }^{92}$ Isto significa que a eventual tutela pelo direito de autor é algo ténue e evanescente. Com efeito, essa tutela alcança somente a apresentação, sob uma forma individualizada, da sequência de instruções que se faz mister transmitir para a máquina possa desempenhar a função utilitária industrial que lhe é inerente; mas não protege essa função utilitária. J. P. REMÉDIO MARQues, Biotecnologia(s) e Propriedade
} 
Nesse caso, como a expressão é "escrava" da função, falece qualquer proteção de tais programas pelo direito de autor ${ }^{93}$. Ora, são precisamente os elementos funcionais do programa aqueles que conferem um decisivo valor merceológico a esse programa (v.g., as estruturas de dados, o algoritmo, os métodos de operação, os conceitos matemáticos), bem como a forma como executa as funções e as características funcionais inerentes a esse exercício, tais como a precisão de funcionamento, a velocidade com que realiza as tarefas, os recursos de memória, a facilidade de manutenção, a interoperabilidade com outros programas etc. ${ }^{94}$.

Ao que acresce o facto de os concorrentes do titular - que tiverem adquirido, legitimamente, em Portugal, uma cópia do programa (p. ex., por meio da aquisição de máquinas de jogo ${ }^{95}{ }^{96}$, aí onde cópias de tais programas estejam introduzidas, atento o esgotamento dos direitos de autor por meio da aquisição de exemplares corpóreos ${ }^{97}$ ) —

Intelectual, vol. I, 2007, cit., p. 137, nota 265; Ph. GAUDRAT, "La protection des logiciels par la propriété littéraire et artistique", in: RIDA, 1986, p. 181 s., p. 185. O requisito da originalidade é minimalista (qual originalidade fraca alicerçada numa geometria variável: J. P. REMÉDIO MARQUES, ob. cit., vol. I, 2007, p. 129), no sentido em que o programa é original se resultar do esforço do criador, ou seja, se não for banal ou trivial na indústria dos suportes lógicos - A. Dias PereIRA, Direitos de Autor e Liberdade de Informação, 2008, cit., p. 406; T. DREIER, in: DreIER/SCHULTZE, UrhG, Kommentar, 3. ${ }^{a}$ ed., 2008, cit., p. 1001; M. LEHMANN, in: U. LOEWENHEIM, Handbuch des Urheberrechts, 2. ${ }^{a}$ ed., 2010, cit., § 76, anotação à margem n. ${ }^{\circ}$ 3, p. 1861.

${ }^{93}$ J. P. REMÉDIO MARQUES, Biotecnologia(s) e Propriedade Intelectual, vol. I, 2007, cit., p. 127, nota 250 (quanto maiores forem os constrangimentos colocados no processo criativo relativamente aos procedimentos técnicos ou às funções técnicas ou resultados a atingir, menor será o acervo de escolhas criativas do autor), idem, vol. I, pp. 129-130, nota 259, p. 132, nota 263, com referências à bitola ou nível de conteúdo de originalidade exigível para a tutela autoral dos programas de computador; tb. José Alberto VieIRA, A Proteção dos Programas de Computador pelo Direito de Autor, 2005, pp. 814-815.

${ }^{94}$ José Alberto VieIRA, A Proteção dos Programas de Computador pelo Direito de Autor, 2005, cit., p. 287.

${ }^{95} \mathrm{Ou}$, inclusivamente, por meio da aquisição, em Portugal, de CD-ROM, CD-I, bandas magnéticas ou outros suportes corpóreos que contenham cópias dos programas.

${ }^{96}$ Pressupõe-se que essa aquisição tenha sido efectuada com o consentimento do alegado titular dos direitos de autor relativos aos programas de computador.

${ }^{97}$ Isto porque o esgotamento do direito de autor sobre o programa de computador também ocorre com os actos de disposição do programa que não impliquem a distribuição deste através de suportes corpóreos. Será, por exemplo, o caso vulgar de distribuição das máquinas de jogo em cujo hardware os programas de computador estão integrados, ou a instalação dos programas directamente no disco rígido ou num "mainframe" ou, ainda, as eventualidades em que os programas são transmitidos em linha para o 
ISSN ELETRÔNICO 2316-8080

PATENTES DE PROGRAMAS DE COMPUTADOR E DE SISTEMAS INFORMÁTICOS DE JOGOS

ELETRÔNICOS PATENTES DE MÉTODOS DE EXERCÍCIO DE ACTIVIDADES ECONÔMICAS?

poderem livremente fazer a descompilação do programa protegido, ou seja, ficam eles salvos de observar, estudar e testar o funcionamento do programa eventualmente protegido, a fim de obter informações indispensáveis à criação de outros programas originais, ainda que compatíveis e interoperáveis com o primeiro (artigo $7 .^{\circ}, \mathrm{n}^{\circ}$, do Decreto-Lei n. ${ }^{\circ}$ 252/94, de 20 de outubro).

\section{Conclusão}

Tão logo que uma solução (conquanto no domínio dos jogos ou do exercício de actividades económicas) seja implementada por meio de um programa de computador, é difícil recusar-lhe o carácter técnico, o contributo técnico ou a tecnicidade inerente ao mode de ser de um quid a que chamados invenção, não sendo assim atingida pelas exclusões previstas no art. $52 .^{\circ}$, n. $^{\circ} 2$, da $\mathrm{CPE}$ - pois ocorre uma interação entre as instruções (o programa) e a máquina ou sistema informático em linha provida de alterações fisicas e tangíveis após a execução das instruções.

Todavia, ao responder afirmativamente à questão sobre se existe invenção, isso não significa alcançar o patamar da concessão da patente, uma vez que tais meios técnicos, ainda quando incidam sobre um domínio da tecnologia tradicionalmente aceito no direito de patente, podem não exibir a suficiente distância entre o estado da técnica e a concreta solução reivindicada. Pois o programa - qualificável, num primeiro momento, como invenção - pode apenas permitir, num segundo momento de sindicação, uma "normal" interação física entre as instruções e a máquina desprovida de actividade inventiva (ou nível inventivo).

A tutela por direito de autor é uma alternativa interessante, por vezes, para o titular. Este não tem, neste caso, de divulgar o código-fonte, contrariamente ao que ocorre na descrição, por ocasião do depósito de pedidos de patente.

Porém, o direito de autor apenas protege a apresentação, sob uma forma individualizada, da sequência de instruções que se faz mister transmitir para a máquina

computador do utilizador (adquirente por venda, doação, permuta etc.) - cfr. JOSÉ ALBERTO VIEIRA, $A$ Proteção dos Programas de Computador pelo Direito de Autor, 2005, cit., pp. 645-646. 
possa desempenhar a função utilitária industrial que lhe é inerente; este exclusivo intelectual não protege essa função utilitária.

\section{SIGLAS E ABREVIATURAS}

Acordo TRIPS — Acordo sobre os Aspectos de Propriedade Intelectual Relacionados com o Comércio(1994)

BGH Bundesgerichtshof (Supremo Tribunal Federal alemão)

BPatG Bundespatentgericht (Tribunal Federal de Patentes)

CDA Código do Direito de Autor e dos Direitos Conexos (Portugal)

cit. citado

CPE Convenção sobre a Patente Europeia

F.3d - Federal Supplement, third series

GRUR Gewerblicher Rechtschutz und Urheberrecht

GRUR Int - Gewerblicher Rechtschutz undUrheberrecht Internationaler Teil

EIPR

IEP European Intellectual Property Review

Instituto Europeu de Patentes

INPI Instituto Nacional da Propriedade Industrial

ivi mesmo local

Mitt Mitteilungen des deustchen Patentanwälte

NJW N New Juristische Wochenschrift

p. ex. por exemplo

RG Reichgericht

RIDA - Revue internationale de droit d'auteur

R.P.C. - Report of Patent Cases

ss. $\quad$ seguintes

U.S.C. $\quad$ United States Codes

UWG Gesetz gegen den unlauteren Wettbewerb

WRP Wettbewerb in Recht und Praxis (Zeitschrift)

Recebido 13/01/2016

Aprovado 25/01/2016

Publicado 29/02/2016 